\title{
I. Familien im demographischen und gesellschaftlichen Wandel
}

In der zweiten Hälfte des 20. Jahrhunderts veränderten sich die Familienstrukturen in Deutschland stark. Heiratsmüdigkeit, Scheidungsboom und „Pillenknick“ sind Schlagworte, die auf tiefgreifende Wandlungsprozesse verweisen. Teilweise können diese Veränderungen auf langfristige demographische Trends seit dem Ende des 19. Jahrhunderts zurückgeführt werden. Darüber hinaus hinterließen aber auch historische Ereignisse - allen voran die Weltkriege und ihre Folgen tiefgreifende Spuren. Ein erheblicher Teil der Veränderungen erklärt sich auch aus dem Faktor "Wertewandel", der etwa seit Mitte der sechziger Jahre zu einer Änderung des individuellen Verhaltens in Familienfragen führte. Das folgende Kapitel geht der Frage nach dem Ablauf der Wandlungsprozesse und den Wirkungsanteilen der unterschiedlichen Faktoren nach.

Erste Indikatoren für die Veränderungen sind die demographischen Kerndaten, in denen sich der Rückgang der Eheschließungen und Geburten sowie der gleichzeitige Anstieg der Ehescheidungen spiegelt. ${ }^{1}$ Empirische Daten für die demographische Analyse lassen sich relativ leicht finden. Die amtliche Statistik, insbesondere die Volkszählungen von 1950, 1961 und 1970, bilden eine ausführliche Grundlage für Untersuchungen. Hinzu kommen die Erhebungen des seit 1957 jährlich durchgeführten Mikrozensus. Allerdings stehen heute nur solche Daten zur Verfügung, die damals erhoben wurden. Das Profil der verfügbaren statistischen Informationen hängt also von den Fragen der zeitgenössischen Statistiker ab.

Die Bedeutung dieser Einschränkung wird beispielsweise deutlich, wenn man den Blick auf Randbereiche der generationenübergreifenden Lebensgemeinschaften richtet, die zentrale Kriterien der traditionellen Familiendefinition nicht erfüllten. Gemeint sind damit neben entfernter verwandten Personen, die in einem gemeinsamen Haushalt zusammenlebten - beispielsweise Großeltern mit ihren Enkeln -, vor allem ledige Frauen mit Kindern. Ledige Mütter und ihre unehelichen Kinder galten bis Anfang der sechziger Jahre nicht als Familien. ${ }^{2}$

1 Die Historische Familienforschung ist seit den achtziger Jahren ein etablierter Forschungszweig der Geschichtswissenschaft. Daneben existiert eine breite familiensoziologische Forschung. Eine Untersuchung der Entwicklung der Familien in Westdeutschland für den Zeitraum 1945-1960, die die Ergebnisse beider Forschungsbereiche integriert, bietet Niehuss, Strukturgeschichte. Knappere Überblicke für den Zeitraum von 1945 bis in die achtziger bzw. neunziger Jahre finden sich bei Meyer/Schulze, Frauen sowie Korte, Bevölkerungsstruktur, vgl. neuerdings auch Bernöster, Grundlagen, insbesondere S. 2753. Franz Rothenbacher erstellte ein Datenhandbuch über die Haushalts- und Familienstatistik, das die amtlichen Umfrageergebnisse seit 1815 unter einheitlichen Kriterien zu langen Datenreihen zusammenstellte. Rothenbacher, Haushalts- und Familienstatistik, für die Bundesrepublik vgl. S. 337-353. Eine kritische Analyse der Entwicklung der amtlichen Familienstatistik gibt Niehuss, Spiegel.

2 Niehuss, Strukturgeschichte, S. 19. 
Die in Volkszählungen erhobenen Daten sind zudem Querschnittsdaten. Sie stellen eine Momentaufnahme zum Zeitpunkt der Befragung dar und erfassen dabei die Familien in ihren jeweiligen unterschiedlichen Lebensphasen: junge Ehepaare, die noch keine Kinder haben, Familien mit Kindern und ältere Eltern, deren Kinder schon erwachsen sind. Für eine Untersuchung des Wandels der Familienstrukturen wäre es nun besonders interessant, aus diesen synchronen Querschnittsdaten diachrone Familienzyklen von der Eheschließung über die Kinderphase bis zur Auflösung der Familie zu rekonstruieren, um zu erfahren, wie sich die Familienzyklen im Laufe der Zeit veränderten. Aufgrund der Fluktuation und der hohen Aggregierung der Daten ist dies aber unmöglich. Das „FamilienzyklusKonzept" muß statt dessen individuelle biographische Einzelfalldaten heranziehen, die die Volkszählungen in der Bundesrepublik in der Regel nicht ermittelt haben. ${ }^{3}$ Nur ein einziges Mal zu Anfang der siebziger Jahre wurden in einer Volkszählung und dem nachfolgenden Mikrozensus in Westdeutschland alle verheirateten, geschiedenen und verwitweten Frauen nach ihrer Geburtenzahl und dem Geburtsjahr befragt und damit ihre individuellen "Geburtenbiographien“ erstellt. ${ }^{4}$ Ähnlich differenzierte Untersuchungen gab es später nicht mehr, so daß das Konzept nur bis zu der Gruppe der Frauen anwendbar ist, die Anfang der siebziger Jahre ihre Kinderphase abgeschlossen hatte. Für einen Vergleich mit späteren Generationen fehlt das statistische Material.

Die demographischen Daten geben bereits erste Hinweise auf die Ursachen der Veränderungen, denn sie schufen Rahmenbedingungen für die weitere Entwicklung und entfalteten auf diese Weise ein gewisses Maß an Eigendynamik, das der bundesdeutsche Familienpolitikexperte Max Wingen als „Gesetz der demographischen Trägheit" bezeichnete. ${ }^{5}$

Ein Beispiel mag den Effekt verdeutlichen: Der Geburtenrückgang während des Zweiten Weltkriegs führte dazu, daß es etwa 20 Jahre später, als diese Kinder erwachsen geworden waren, zu einem weiteren Rückgang der Geburten kommen mußte. Selbst wenn die Frauen genauso viele Kinder bekamen, wie traditionell üblich, mußte sich der Geburteneinbruch in der nächsten Generation fortsetzen, weil es weniger junge Eltern gab. Um die Bevölkerungsentwicklung stabil zu halten, hätten diese Frauen nicht nur genauso viele, sondern mehr Kinder bekommen müssen, als bis dahin üblich.

Fragt man nach weiteren Ursachen der Entwicklung, dann müssen die demographischen Faktoren wie geburtenstarke oder -schwache Jahrgänge, aber auch Wanderungsbewegungen und der kriegsfolgenbedingte Männermangel aus den statistischen Daten herausgerechnet und die so bereinigten Daten untersucht werden. Die Eheschließungen gingen zurück - verweigerten tatsächlich immer mehr junge Menschen den Bund fürs Leben oder gab es einfach weniger junge Menschen in der Bundesrepublik, die jedoch weiterhin im selben Maß heirateten? Die Zahl der Geburten war rückläufig - hatten die Frauen tatsächlich weniger Gebur-

3 Vgl. zu den methodischen Problemen Höhn, Implikationen, S. 58.

4 Volkszählung 1970 und anschließender Mikrozensus, vgl. Niehuss, Strukturgeschichte, S. 21.

5 Wingen, Perspektiven, S. 8, zitiert nach Bernöster, Grundlagen, S. 31. 
ten oder gab es weniger junge Frauen? Die Zahl der Scheidungen stieg - wurden Ehen tatsächlich immer bereitwilliger geschieden oder korreliert der Anstieg der Scheidungen mit einem vorherigen Anstieg der Eheschließungen, so daß die Quote der Scheidungen letztlich gleich blieb? Komplizierte Berechnungen sind für eine solche Bewertung notwendig. Sie zeigen, daß sich etwa ab Mitte der sechziger Jahre zusätzlich zu den demographisch verursachten Tendenzen eine Verhaltensänderung vollzogen hat.

Wirft schon die quantitative Interpretation der Daten Probleme auf, so verstärken sich die Schwierigkeiten, wenn man nach den qualitativen Ursachen der Veränderungen fragt. Daß die wirtschaftlichen Verhältnisse, der technische und medizinische Fortschritt und der Wandel von Werten und Leitbildern von Bedeutung für die Veränderung der Familie waren, ist wohl unbestritten. Die komplizierten Wechselwirkungen zwischen veränderten Rahmenbedingungen und dem Wandel der Familie sind aus den zur Verfügung stehenden statistischen Daten aber kaum zu erschließen. So ist es beispielsweise hochumstritten, ob die Erwerbstätigkeit der Ehefrauen und Mütter ein Grund für den Geburtenrückgang war, oder ob der Wirkungszusammenhang genau umgekehrt funktionierte, also die geringere Kinderzahl eine Bereitschaft für Berufstätigkeit schuf. 6 Für diese Ursachenforschung hält die amtliche Statistik so gut wie keine Daten bereit. Daher müssen familiensoziologische Untersuchungen auf außeramtliche Umfragen und anderweitig erhobene Daten zurückgreifen. ${ }^{7}$ Diese können aber in der Regel nur mit kleinen Stichproben arbeiten und daher nicht dieselbe Repräsentativität beanspruchen wie die Ergebnisse einer Volkszählung.

Die folgende Darstellung bezieht sich im allgemeinen auf die Entwicklung in der Bundesrepublik als ganzes, denn insgesamt gesehen zeigt der Wandel der Familienstrukturen in Bayern keine signifikanten Abweichungen von der bundesweiten Entwicklung. ${ }^{8}$ Nicht in den sozialen Herausforderungen, sondern vor allem im Hinblick auf die familienpolitische Antwort darauf unterschied sich die bayerische Landesfamilienpolitik von der Bundesebene. Daher sollen im folgenden nur einzelne Probleme wie der Anstieg der Scheidungen und die Frage der Betreuung der Kinder erwerbstätiger Mütter, die für die spätere Untersuchung von besonderer Bedeutung sind, anhand der bayerischen Daten vertieft untersucht werden.

6 Vgl. dazu beispielsweise Beck-Gernsheim, Kinderfrage.

7 In einem breit angelegten Projekt unter der Leitung von Rosemarie Nave-Herz an der Universität Oldenburg wurden beispielsweise in den achtziger Jahren umfangreiche Befragungen zur Veränderung der Familienstrukturen seit 1950 durchgeführt. Die Ergebnisse sind publiziert in den beiden Bänden: Nauck, Erwerbstätigkeit, und Nave-Herz, Familiäre Veränderungen. Eine Zusammenfassung und methodische Einführung bietet Nave-Herz, Familiale Veränderungen.

8 Vgl. zur Entwicklung der Familienstrukturen in Bayern von Kriegsende bis Mitte der siebziger Jahre Kuller, Stiefkind, S. 274-300. 


\section{Veränderung von Familienstrukturen}

\section{Die langen Schatten der Nachkriegszeit}

Im nachhinein betrachtet erscheint die Zeit vom Kriegsende 1945 bis zu den frühen sechziger Jahren als eine Phase der Stabilisierung der traditionellen Familienstrukturen. Die Eheschließungszahlen stiegen, die Scheidungszahlen sanken nach einem kurzfristigen Anstieg nach Kriegsende wieder auf ein niedriges Niveau, die Zahl der Geburten nahm zu. Viele neuere Studien zur "Krise der Familie“ in der Bundesrepublik setzen daher erst mit der Entwicklung seit den sechziger Jahren ein. ${ }^{9}$

Dennoch wies auch der erste bundesdeutsche Familienminister Franz-Josef Wuermeling Anfang der fünfziger Jahre stets auf die Gefährdungen der Familie hin. Und das nicht ohne Grund. Fast vergessen sind heute die Probleme der Kriegs- und Nachkriegszeit, die kurz- und langfristig die Familienstrukturen prägten. ${ }^{10}$ Es begann damit, daß viele Paare ihre Familienpläne während des Krieges aufgeschoben hatten. Heirats- und Geburtenausfall, aber auch die Hinausschiebung von Scheidungen prägten die Familienstatistik der Kriegsjahre. Das NS-Regime hatte durch seine Verfolgung viele Familien zerstört und teilweise mit Kind und Kindeskind ausgelöscht. Im Zuge der großen Migrationsbewegungen während und nach dem Krieg wurden Familien oft räumlich auseinandergerissen und auf Jahre hinaus getrennt. Eine einschneidende Wirkung hatten auch die Millionen Kriegsopfer. Kaum eine Familie in Deutschland, die nicht den Verlust mindestens eines Familienangehörigen zu beklagen hatte. Gerade in einer Zeit, in der verwandtschaftliche Solidarität eine existenzerhaltende Bedeutung gewinnen konnte, standen viele Menschen vor den Trümmern ihrer Familie.

Der Zweite Weltkrieg und seine Folgen erschütterten die demographische Struktur der deutschen Gesellschaft. Eine langfristig für die Familienentwicklung in Deutschland in vielfacher Hinsicht bedeutsame Folge des Krieges war der Frauenüberschuß. 1946 lebten in Deutschland rund 7,4 Millionen mehr Frauen als Männer. ${ }^{11}$ Die Kriegstoten sowie die vermißten und die in Kriegsgefangenschaft geratenen Soldaten hatten das Geschlechterverhältnis erheblich aus dem Gleichgewicht gebracht. Bis Anfang der fünfziger Jahre entschärfte sich die Situation zwar, da nun viele kriegsgefangene Männer zurückkehrten. Aber noch in der Volkszählung von 1950 zeigte sich ein deutlicher Männermangel. Auf 100 Frauen im Alter zwischen 15 und 65 Jahren kamen nur rund 81 Männer. ${ }^{12}$

Die Verschiebung im Geschlechterverhältnis traf die jüngeren und mittleren Altersgruppen besonders stark. Unter den 25- bis 39jährigen Frauen standen 100

\footnotetext{
9 Vgl. beispielsweise Mayer, Krise.

10 Vgl. dazu allgemein Castell, Konsequenzen.

11 Diese Zahl ermittelte die Volkszählung 1946. Die Daten sind jedoch unter schwierigen Umständen, teilweise nicht vollständig und auch nicht nach einheitlichen Kriterien erhoben worden. So zählte die britische Zone die ortsanwesende Bevölkerung, während in den drei anderen Zonen die Wohnbevölkerung ermittelt wurde. Vgl. dazu Niehuss, Strukturgeschichte, S. 34.

12 Castell, Konsequenzen, S. 121.
} 
Frauen nur 71 Männer gegenüber. Im Laufe der Jahre wuchsen jedoch Jahrgänge heran, in denen es keine geschlechtsspezifischen Kriegsverluste gab. So verschob sich das aus dem Zweiten Weltkrieg stammende Ungleichgewicht zwischen Männern und Frauen mit dem Älterwerden der Betroffenen in der Bevölkerungspyramide nach oben, bis es bei der Volkszählung 1970 nur noch den Bevölkerungsteil betraf, der über 45 Jahre alt war. Dieses Datum stellt eine gewisse Zäsur dar, da Frauen über 45 Jahren in der Regel keine Kinder mehr bekommen und insofern auch keine Familie mehr gründen. Ein Übergewicht an Frauen in der älteren Generation gab es in der Bundesrepublik noch bis in die achtziger Jahre hinein, was unter anderem dadurch verstärkt wurde, daß die Männer, die vor 1900 geboren waren und an beiden Weltkriegen teilgenommen hatten, von den Kriegsfolgen im Alter zunehmend geschwächt waren: Sie hatten eine weit über das natürliche Maß hinaus niedrigere Lebenserwartung als gleichaltrige Frauen. ${ }^{13}$

Das Ungleichgewicht der Geschlechter war nicht nur ein vorübergehendes Kriegsfolgeproblem, das lediglich im Leben der unmittelbar Betroffenen eine Rolle spielte. Die demographischen Zäsuren des Zweiten Weltkrieges hatte jahrzehntelange Auswirkungen, die teilweise bis heute spürbar sind. Mit ihrem Einfluß auf Heiraten und Geburten ragten die Wirkungen weit über die erste Generation hinaus. Betrachtet man beispielsweise die Situation auf dem Heiratsmarkt in der Altersgruppe der 20- bis 50jährigen, dann zeigt sich, daß in der Bundesrepublik Deutschland das zahlenmäßige Verhältnis zwischen unverheirateten Männern und Frauen nur für einen sehr kurzen Übergangsmoment Anfang der sechziger Jahre annähernd ausgeglichen war. Bis Ende der fünfziger Jahre sorgte der kriegsfolgenbedingte Männermangel für ein Übergewicht an unverheirateten Frauen. Ab Anfang der sechziger Jahre kippte die Lage ins andere Extrem und es gab mehr unverheiratete Männer als Frauen. Diese Situation hielt bis in die achtziger Jahre an. ${ }^{14}$

Ein wichtiger Faktor für diese Entwicklung war das Geschlechterungleichgewicht der Nachkriegszeit. Die Situation pflanzte sich dann über Generationen weiter fort, denn jede Alterskohorte traf auf bereits vorstrukturierte soziale Verhältnisse: Der Männermangel nach dem Krieg führte zunächst dazu, daß junge Frauen zunehmend Männer heirateten, die nicht nur - wie traditionell üblich - ein bis drei, sondern fünf bis sieben Jahre älter waren als sie selbst. Bis in die fünfziger Jahre mußten sich die jungen Frauen zwangsläufig in einer älteren Männerkohorte einen Partner suchen. Zu dieser Zeit sank auch das durchschnittliche Heiratsalter. Als sich der Altersabstand zwischen den Ehepartnern mit der Zeit wieder auf ein bis drei Jahre einpendelte, stand ab Anfang der sechziger Jahre den Männern im Alter von Mitte zwanzig eine entsprechende Frauenkohorte gegenüber, die bereits zum großen Teil mit deutlich älteren Männern verheiratet war. Da die Frauen sich offenbar ganz überwiegend einen Mann gesucht hatten, der älter war als sie selbst,

$13 \mathrm{Vgl}$. zu dieser Argumentation Paula, Altersaufbau, S. 379.

14 Zum Heiratsmarkt werden alle unverheirateten Personen gerechnet, unabhängig davon, ob sie ledig, verwitwet oder geschieden sind. Also gehen auch die zahlreichen Soldatenwitwen der Nachkriegszeit in die Berechnungen ein. Vgl. dazu und zur folgenden Argumentation Klein, Heiratsmarkt, und Niehuss, Strukturgeschichte, S. 344-350. 
und lieber einen relativ großen Altersabstand akzeptierten als einen gleichaltrigen oder gar einen jüngeren Mann zu heiraten, waren diese jungen Männer nun gezwungen, sich ihrerseits nach einer jüngeren Partnerin umzusehen, was zum weiteren Absinken des Heiratsalters beitrug. Das veränderte Heiratsverhalten läßt sich aus dieser Perspektive - zumindest teilweise - auch als eine strukturbedingte „Notlösung " interpretieren. ${ }^{15}$

Einschränkend muß gesagt werden, daß diese Überlegungen von einem gleichbleibenden Heiratswunsch ausgehen. Trotz dieses Einwands und obwohl das Heiratsverhalten auch noch von zahlreichen weiteren Beweggründen abhängt, müssen die zeitweise drastisch unausgeglichenen Heiratsmärkte in der Bundesrepublik als ein wichtiger Faktor für die Heiratsmöglichkeiten, für das Partnerwahlverhalten und den Altersabstand zwischen den Ehepartnern, für die Stabilität bestehender Ehen, aber auch für die Berufsorientierung von Frauen angesehen werden. ${ }^{16}$

Es war nach dem Kriegsende auch absehbar, daß eine erhebliche Zahl von Frauen überhaupt keinen Ehepartner finden würde. 1950 schätzten Statistiker, daß in der Bundesrepublik zwischen 1,7 und zwei Millionen Mädchen und Frauen im Alter zwischen 15 und 45 Jahren - das war die Bevölkerungsgruppe, die am stärksten betroffen war, und gleichzeitig die Schlüsselgruppe für die zukünftige Familien- und Geburtenentwicklung - infolge des Zweiten Weltkriegs keine Ehe eingehen konnten, die unter anderen Umständen geheiratet hätten bzw. verheiratet geblieben wären, letzteres betraf vorwiegend die Kriegswitwen. Das bedeutete: Etwa jede vierte Frau im Alter zwischen 15 und 45 Jahren mußte gegen ihren Wunsch ohne Ehemann bleiben. ${ }^{17}$

Unverheiratet zu sein bedeutete für die Frauen eine tiefgreifende Umstellung ihrer Zukunftsaussichten, denn das gesellschaftliche Leitbild einer ledigen Frau unterschied sich erheblich von dem einer Ehefrau und Mutter:18 Verheiratete Frauen hatten einen eigenen Haushalt, alleinstehende in der Regel nicht - sie lebten bei Verwandten. Verheiratete Frauen führten ein emotionales und sexuelles Leben in ihrer Partnerschaft, ledige Frauen durften nur Freundschaften unterhalten, sollten aber der sexuellen Beziehungen entsagen. Verheiratete Frauen hatten Kinder, unverheiratete sollten keine Kinder haben. In der Folge war also auch ein demographisch bedingter Geburteneinbruch zu erwarten. Die Statistiker befürchteten einen Ausfall von rund zwei bis 2,5 Millionen Geburten. ${ }^{19}$ Angesichts dieser Prognose geburtenschwacher Jahrgänge in den folgenden 30 Jahren drohte auch dieses Problem seine Schatten weit über die Generationengrenze hinweg zu werfen. Und schließlich: Ledige Frauen - zumindest aus der Arbeiterklasse - arbeiteten im Gegensatz zu ihren verheirateten Geschlechtsgenossinnen den ganzen Tag außer Haus. Vor allem der letzte Aspekt stieß in der Praxis auf Probleme: Diese

15 Niehuss, Strukturgeschichte, S. 350.

16 Klein, Heiratsmarkt, S. 366.

$17 \mathrm{Vgl}$. dazu Roscher, Frauenüberschuß. Dort findet sich neben den bayerischen Daten auch ein Überblick über die bundesweite Situation, insbesondere S. 15.

$18 \mathrm{Zu}$ den folgenden vier Kategorien vgl. Heineman, Difference, S. 5.

19 Vgl. Roscher, Frauenüberschuß, S. 15. 
begannen mit der Frage der Berufsausbildung, setzten sich fort mit der Suche nach einer dauerhaften Erwerbstätigkeit, die eher der "Normalbiographie“ von Männern entsprach und für Frauen nur in bestimmten Berufssparten möglich war, und mündeten schließlich nicht selten in das Problem einer geschlechtsspezifischen Altersarmut, weil die sozialstaatliche Versorgung in den Bereichen der Frauenerwerbstätigkeit vielfach unzureichend war. Auch das gesellschaftliche Ansehen einer ledigen Frau war geringer als das einer Ehefrau und Mutter, ein Befund, der sich in der Nachkriegszeit trotz, oder vielleicht in gewissem Maße auch aufgrund der gewachsenen Zahl der alleinstehenden Frauen noch verstärkte. ${ }^{20}$

Aber nicht nur die ledigen Frauen stellte der Männermangel vor grundsätzliche Fragen. Auch verheiratete Frauen, deren Männer vermißt waren, mußten neben der emotionalen Belastung oft Jahre der ökonomischen und rechtlichen Unsicherheit aushalten. Viele Ehemänner kehrten überhaupt nicht zurück. Eine besonders von den Kriegsfolgen betroffene Bevölkerungsgruppe waren die schätzungsweise 1,2 Millionen Witwen, ${ }^{21}$ unter ihnen viele Mütter mit kleinen Kindern. Die Kriegswitwen und -waisen bildeten die erste große Gruppe von sogenannten Rumpffamilien der deutschen Nachkriegsgeschichte. Sie befanden sich in der Regel in einer sehr schwierigen sozialen und wirtschaftlichen Lage.

Auch auf das Leben der Kinder wirkte der langjährige und oft endgültige Verlust des Vaters prägend. ${ }^{22}$ Die meisten der in den späten dreißiger und frühen vierziger Jahren geborenen Kinder verbrachten die ersten Lebensjahre ohne Vater. In vielen Fällen kam der Vater auch gar nicht wieder zurück, weil er gefallen oder vermißt war. Rund ein Viertel aller Kinder wuchs nach dem Zweiten Weltkrieg ohne Vater auf. Dadurch fehlte den Kindern eine der elterlichen Bezugspersonen, und zwar diejenige, die in der traditionellen Familienstruktur Autorität und Strenge verkörperte. Die Kinder erlebten nicht selten einen Widerspruch zwischen tatsächlicher Freiheit, die ihnen aufgrund der Überlastung der Mutter im allgemeinen offen stand, und den normativ aufrechterhaltenen Erziehungsstandards. Die Wiederherstellung „anständiger Autoritätsverhältnisse“ in den fünfziger Jahren nach der Rückkehr vieler Väter und der allgemeinen Normalisierung der Lebensverhältnisse, die es den Müttern erlaubte, sich wieder stärker um die Erziehung der Kinder zu kümmern, traf diese Kinder und Jugendlichen ungefähr während der Pubertät und war für sie eine unerwartete, schwierige Erfahrung. Man kann festhalten, daß es zwar in den fünfziger Jahren keine grundlegenden Umorientierungen in den Erziehungszielen gab, daß sich jedoch die Wirklichkeit

$20 \mathrm{Vgl}$. zum gesellschaftlichen Ansehen alleinstehender Frauen, vor allem im Hinblick auf die Sexualmoral, Heineman, Difference, S. 232-236.

21 Niehuss, Strukturgeschichte, S. 116-122, die der Situation der Kriegswitwen als "typischem Nachkriegsschicksal" einen Abschnitt widmet. Die Zahl der Kriegswitwen wurde offiziell nicht ermittelt. Rentenberechtigt waren 1950 nur 890000 Witwen (ohne das Land Berlin). Diese Zahl erfaßte jedoch nicht die erwerbstätigen Witwen. Zur Erfahrungsdimension siehe: Meyer/Schulze, Liebe; dies., Alleinstehende Frauen; dies., Veränderungen; Meyer, Krieg im kleinen; Delille/Grohn, Blick. Neuerdings: Heineman, Difference.

22 Vgl. zum folgenden Fischer-Kowalski, Halbstarke; Willenbacher, Zerrüttung, S. 602, 613; Schütze/Geulen, Nachkriegskinder, S. 29-40. 
der Erziehung erheblich veränderte, da die Eltern bzw. Elternteile Anspruch und Handeln wieder stärker in Einklang bringen konnten.

In der Zeit der Abwesenheit der Väter entwickelte sich zwischen Müttern und Kindern oft eine sehr enge Bindung. In den letzten Kriegsmonaten und der Nachkriegszeit, in der viele gesellschaftliche Strukturen zerfallen waren, bildeten diese Mutter-Kind-Gemeinschaften als Rumpffamilien einen sozialen und emotionalen Bezugspunkt, an den sich nicht nur die Kinder, sondern auch die Mütter klammerten. ${ }^{23}$ Inwieweit daraus eine emotionale Überforderung für die Kinder erwuchs, die eine ganze Generation prägte, mag umstritten bleiben. Fest steht allerdings, daß es für zurückkehrende Väter und für neue Ehepartner manchmal nicht leicht war, ihre Rolle in der Familie zu übernehmen. Andererseits waren die Kinder, die ihre Väter kaum kannten, nicht selten das einzige verbindende Element für die durch jahrelange Trennung entfremdeten Eltern.

In besonderer Schärfe zeigten sich die Probleme bei den Evakuierten und Flüchtlingen. ${ }^{24}$ Wenn der Vater aus dem Krieg zurückkehrte, mußte er sich auf die Suche nach seiner Familie machen, und oft dauerte es lange, bis die zerstreute Familie räumlich und emotional wieder zusammenfand. Das Problem, den Aufenthaltsort der Angehörigen ausfindig zu machen, und die Schwierigkeiten der Existenzgründung in einer neuen Heimat dürften dabei eine entscheidende Rolle gespielt haben.

Diese Beobachtungen lenken den Blick auf die Frage, welche weiteren Strukturbedingungen das Leben von Familien in der unmittelbaren Nachkriegszeit bestimmten. Hier ist neben der Arbeitsmarktsituation vor allem die Wohnungsnot zu nennen. ${ }^{25}$ Wohnungen als Lebensraum für Familien waren in der unmittelbaren Nachkriegszeit ein äußerst knappes Gut. Häufig waren sie nicht am selben Ort verfügbar wie ein Arbeitsplatz. Dies führte zur räumlichen Trennung von Familien, was sich auch in der amtlichen Statistik spiegelt und diese verzerrt. Während der "Ernährer" der Familie beispielsweise nahe seinem Arbeitsplatz in einer Stadt wohnte, hatten die restlichen Familienmitglieder ihren Wohnort in ländlicher Region, wo mehr Wohnraum verfügbar war. So konnte es erscheinen, als ob die Familie getrennt lebe, während doch nur die äußeren Umstände getrennte Haushalte notwendig machten. Hinzu kam, daß in der Zeit der Zwangsbewirtschaftung jeder offiziell gemeldete Haushalt Anspruch auf bestimmte Bewirtschaftungsgüter, z.B. Heizstoffe und Lebensmittel, hatte. Dies bestärkte den Trend zur Gründung kleiner Einzelhaushalte. Nach der Aufhebung der Bewirtschaftung kam es zu einem sprunghaften Anstieg der Mehrpersonenhaushalte und einem starken Rückgang der Ein-Personen-Haushalte. ${ }^{26}$

23 Der Soziologe Gerhard Wurzbacher konstatierte eine neue, „personenorientierte“ Beziehung zwischen Eltern und Kindern, die die Kinder als individuelle Wesen und nicht als familiäre Funktionsträger ansah. Wurzbacher, Dorf, S. $175 \mathrm{f}$. Vgl. dazu auch Bude, Kriegskinder; Willenbacher, Zerrüttung, S. 612.

24 Willenbacher, Zerrüttung, S. 602; vgl. allgemein Klee, Luftschutzkeller.

${ }_{25} \mathrm{Vgl}$. dazu ausführlich Niehuss, Strukturgeschichte, S. 42-98.

${ }^{26}$ In Bayern beispielsweise war die Zahl der mittelgroßen Haushalte mit 4 bis 5 Personen 1950 im Vergleich zu 1946 um 14\% angestiegen, die Zahl der Ein-Personen-Haushalte gleichzeitig um $11 \%$ zurückgegangen. Vgl. Krieger, Alter; Niehuss, Sozialgeschichte, S. 928. 
Die Statistiker sahen sich durch die Tatsache, daß Familien auf mehrere Haushalte verteilt waren, vor große Probleme gestellt. Die erste Volkszählung in Deutschland nach Kriegsende im Jahr 1946 legte traditionell den gemeinsamen Haushalt als Maßstab für das Familienleben zugrunde. So kurz nach Kriegsende erwies sich jedoch das bis dahin übliche Konzept des Haushalts als unbrauchbare Größe, denn die Familienstrukturen waren vielfach nicht mehr deckungsgleich mit den Haushaltsstrukturen. ${ }^{27}$ Auf der einen Seite gab es wie erwähnt viele Familien, deren Mitglieder in räumlich getrennten Wohnungen lebten, oft sogar in verschiedenen Orten. Auf der anderen Seite fanden sich häufig Personen in einer Haushaltsgemeinschaft zusammen, die nicht verwandt waren. Die Daten aus dem Jahr 1946 sind durch dieses Defizit gekennzeichnet und bilden daher kaum eine tragfähige argumentative Ausgangsbasis. Erst die Volkszählung von 1950 trug dem Problem Rechnung, indem sie Haushalte nach ihrer Zusammensetzung differenzierte. ${ }^{28}$ Aber erst der Mikrozensus aus dem Jahr 1957, der Probelauf für die Volkszählung 1961, war auf die systematische Erfassung der Zwei-GenerationenFamilie zugeschnitten.

Viele Probleme der Familien in der Nachkriegszeit spiegelten sich gar nicht in den dürren Zahlen der gesamtgesellschaftlichen Statistik: Auch wenn die Familie äußerlich gesehen wieder zusammenfand, auch wenn alle Familienmitglieder wieder in einem gemeinsamen Haushalt lebten, hatten sich doch oft tiefe innere Risse in den Beziehungen zwischen den Ehepartnern und im Verhältnis zwischen den Generationen gebildet. Kehrte der Mann nach langer Abwesenheit in die Familie zurück, dann kam es häufig zu Spannungen und Problemen: Frauen, die jahrelang die alleinige Verantwortung für die Familie getragen hatten, fiel es oft nicht leicht, das Entscheidungsrecht in der Familie wieder abzugeben. Sie hatten auch ein neues Selbstbewußtsein entwickelt, das nicht mehr zum traditionellen Rollenverständnis paßte. Andererseits konnten die von den Strapazen des Krieges und der Gefangenschaft gezeichneten Männer die Erwartungen, die das traditionelle Familienleitbild an sie stellte, nicht immer erfüllen. Gleichzeitig war die gegenseitige Toleranz durch die Erschöpfung beider Partner geringer als in Zeiten niedrigerer Belastung. Durch die lange Trennung und die ganz unterschiedlichen Erfahrungen in dieser Zeit hatten sich die Ehegatten auch häufig verändert und einander entfremdet. Nicht wenige Familien zerbrachen daran, als die Ehemänner zurückkehrten.

Als 1946 die Scheidungsgerichte ihre Arbeit, die sie ab 1943 zunehmend eingeschränkt hatten, wieder aufnahmen, kam es zu einer Scheidungswelle. ${ }^{29}$ Was zeitgenössisch als Ergebnis einer "gelockerten Ehemoral" 30 gedeutet wurde, erwies sich jedoch im nachhinein nur als kurzfristiger Nachkriegseffekt. Viele der jetzt aufgelösten Ehen waren im Krieg übereilt geschlossen worden, dann aber bald ge-

27 Vgl. Niehuss, Strukturgeschichte, S. 16-22.

28 Rothenbacher, Haushalts- und Familienstatistik, S. 20.

29 Vgl. zum folgenden ausführlich Niehuss, Strukturgeschichte, S. 98-106 und 122-127, die die Scheidungen und die unehelichen Geburten als zwei von vier typischen Nachkriegsschicksalen untersucht.

30 Roscher, Alters- und Familienstandsgliederung, S. 30. 
scheitert und nur pro forma aufrecht erhalten worden, solange der Mann an der Front war, zunehmend auch, weil die Scheidungsgerichte in den letzten Kriegsmonaten ihre Arbeit weitgehend eingestellt hatten. Diese Scheidungen waren auf die Zeit nach dem Krieg aufgeschoben worden und trieben nun die Statistik in die Höhe. Besonders 1947 schnellte die Zahl der Scheidungen nach oben, was hauptsächlich mit der Heimkehr von Männern zusammenhing, die sich inzwischen von ihren Frauen entfremdet hatten. Typischer Scheidungsgrund der Nachkriegszeit war dann auch die lange Trennung der Ehegatten. Ein weiteres Phänomen war die rasante Zunahme der unehelichen Geburten. Hintergrund dieser Entwicklung bildete neben dem demographischen Faktor des Männermangels vor allem die wirtschaftliche Unsicherheit, die eine Eheschließung nicht zuließ, selbst wenn ein Kind unterwegs war.

War die traditionelle Familie angesichts dieser Krisensymptome ein Modell ohne Zukunft? Zeitgenössische soziologische Untersuchungen bewerteten die Situation der Familien nach dem Kriegsende ganz unterschiedlich. Auf der einen Seite betonte beispielsweise Hilde Thurnwald 1948 die Instabilität der Familie, während andere Autoren wie Helmut Schelsky im Gegenteil in der Familie einen gesellschaftlichen "Stabilitätsrest" sahen. ${ }^{31}$ Beide Seiten hatten gute Argumente für ihre Thesen.

Thurnwalds Studie befaßte sich mit dem speziellen Berliner Großstadtmilieu und fand dort zahlreiche Hinweise auf die Überforderung und den strukturellen Zerfall der von ihr untersuchten Familien. ${ }^{32}$ Auch aus heutiger Sicht sind die Indikatoren, die auf diesen Prozeß der Desorganisation ${ }^{33}$ hindeuten, nicht zu übersehen: die lange räumliche Trennung von Familienangehörigen, die sehr unterschiedlichen Erfahrungen der Familienmitglieder in der Zeit der Trennung, die innere Entfremdung der Ehepartner voneinander und der Väter von ihren Kindern, die große Zahl der vaterlosen Familien, das Hochschnellen der unehelichen Geburten und der Scheidungen - dies alles schien darauf hinzuweisen, daß die traditionelle Familie aufgrund der äußeren Einflüsse und inneren emotionalen Störungen überfordert war und sich in einer existentiellen Krise befand. Vor dem Hintergrund des Männermangels und angesichts der starken Belastungen der Familien in der "Zusammenbruchgesellschaft" konnten der Anstieg der Scheidungen und die Zunahme der unehelichen Geburten als zwei Faktoren für eine Entwicklung in dieselbe Richtung erscheinen: hin zu einer Gesellschaft, in der die traditionelle Familie ihre zentrale gesellschaftliche Ordnungsfunktion verloren hatte. Letztlich waren dies aber vorübergehende Phänomene. Schon 1947 hatte sich die Quote der unehelichen Geburten wieder deutlich verringert und sank

31 Thurnwald, Gegenwartsprobleme; Schelsky, Wandlungen, S. 13.

32 Vgl. dazu Wirth, Familie, S. 199 f.; Vogel, Familie, S. 44-47.

33 Nach der Theorie des Soziologen René König gab es zwei Kriterien für die krisenhafte Entwicklung von Familien: die Desorganisation, d.h. die mangelnde Stabilität der Familie durch Phänomene wie Kriegsgefangenschaft, Scheidung, emotionale Störungen usw., und die Desintegration, d.h. die Auslagerung von familialen Funktionen wie Ausbildung und soziale Sicherung aus der Familie und ihre daraus resultierende funktionale Aushöhlung. Vgl. König, Materialien. 
dann kontinuierlich weiter bis 1967. Auch der Scheidungsanstieg erwies sich als Nachkriegseffekt und die extrem hohen Werte fielen schon nach kurzer Zeit wieder.

Der Soziologe Schelsky, der seinem Buch ein Sample von Familien zugrunde legte, die sowohl aus dem städtischen als auch aus dem ländlichen Milieu stammten und verschiedene Familienschicksale mit sozialem Abstieg - von Bombengeschädigten über Flüchtlinge bis hin zu sogenannten Deklassierten, die ihre Berufstätigkeit nach Kriegsende aus politischen Gründen aufgeben mußten repräsentierten, betonte im Gegensatz zu Thurnwald vor allem stabilisierende Tendenzen. Seiner Ansicht nach gewannen die Familien in der Nachkriegszeit Funktionen zurück, die sie im Zuge der gesellschaftlichen Modernisierung bereits endgültig verloren zu haben schienen. Da die staatliche Organisation zusammengebrochen war, fielen zentrale Versorgungsfunktionen zwangsläufig wieder an die Familie zurück. Familien bildeten ein letztes funktionierendes soziales Netzwerk für die ökonomische und emotionale Stabilisierung der Menschen. Damit schien ein Prozeß der Moderne in sein Gegenteil verkehrt: die Desintegration - gemeint war damit die zunehmende Auslagerung von Funktionen wie Ausbildung der Kinder und wirtschaftlicher Sicherung der Familienangehörigen aus der Familie. $\mathrm{Da} ß$ es zu diesem Funktionszuwachs der Familie kam, hing auch mit dem sprichwörtlichen Rückzug ins Private zusammen, mit dem weite Teile der deutschen Gesellschaft auf den Zusammenbruch der nationalsozialistischen Herrschaft reagiert hatten.

Bei der Bewertung der Nachkriegszeit gilt es, zwei Phasen zu unterscheiden. In der Zeit vor der Währungsreform fielen zentrale Versorgungsfunktionen zwar an die Familien zurück, diese konnten sie aber unter den schwierigen Umständen und großen emotionalen Belastungen oft kaum bewältigen. Nach der Währungsreform scheinen sich mit den wirtschaftlichen Verhältnissen auch die traditionellen Rollenbeziehungen in den Familien wieder stabilisiert zu haben. Vor allem trennten sich die Rolle des Mannes als „Versorger“ der Familie und die der Frau als „Hausfrau" wieder, nachdem sie in der Notzeit unmittelbar nach dem Kriegsende häufig von den Frauen und Müttern alleine erfüllt worden waren. Mit der Währungsreform, die die Grundlage für das Funktionieren der sozialen Marktwirtschaft bildete, setzte allerdings auch schon wieder eine Gegenbewegung ein, und die Familien gaben ihre Funktionen vermehrt an den Staat und gesellschaftliche Einrichtungen $a b$.

Die meisten zeitgenössischen Autoren argumentierten ähnlich wie Schelsky und betonten eine stabilisierende Funktion der Familie. ${ }^{34}$ Allerdings muß man einschränkend hinzufügen: Wenn zeitgenössisch von Problemen der Familie die Rede war, dann ging es im allgemeinen um die bürgerliche „Vollfamilie“, bestehend aus Vater, Mutter und mehreren Kindern, in der eine klare Rollenverteilung herrschte. Heftige politische Diskussionen entspannen sich um die Frage der Gleichberechtigung der Geschlechter, um das Schwinden der väterlichen Autorität und um die Erwerbstätigkeit der Mutter - alles Punkte, die für die „Vollfami-

34 Baumert, Familien; Schelsky, Wandlungen; Wurzbacher, Leitbilder. 
lie" thematisiert wurden. Andere Familienformen - vor allem die ledigen und verwitweten Mütter mit Kindern - wurden meistens ausgeblendet. ${ }^{35}$ Obwohl es damals eine große Zahl solcher Fälle gab, etablierte sich das Problem alleinstehender Elternteile in der unmittelbaren Nachkriegszeit nicht dauerhaft im öffentlichen Bewußtsein.

Möglicherweise galten die mehreren hunderttausend Kriegswitwen und -waisen nicht als krisenhafte Sonderform der Familie, weil sie im Gegensatz zu ledigen Müttern zuvor verheiratet und damit Mitglieder einer Familie im Sinne des traditionellen Leitbildes gewesen waren, und im Gegensatz zu geschiedenen Frauen nicht durch eigenes "Verschulden“, sondern durch Umstände, die der Staat zu verantworten hatte, in die Situation einer sogenannten unvollständigen Familie geraten waren. ${ }^{36}$ Der Staat fühlte sich daher für ihre Probleme verantwortlich und in der Rolle eines „Ersatzvaters“. Für diese Theorie lassen sich in der Organisation der Familienhilfen innerhalb der Kriegsopferversorgung einige Argumente finden.

Man kann anhand der rechtlichen Regelungen für die Versorgung der Kriegswitwen und -waisen deutlich nachvollziehen, wie das traditionelle Familienleitbild, ergänzt durch „Vater Staat“, in diesem Fall bewußt restauriert wurde. Es orientierte sich an dem christlich-bürgerlichen Ideal, in dem der Vater als „Haupt“ der Familie die höchste Autorität besaß und die Familie nach außen vertrat. Seine wichtigste Funktion war die des „Ernährers“. Die Mutter war dagegen als „Herz“ der Familie für Haushalt und Kindererziehung zuständig. Konkret wirkte sich dieses Leitbild vor allem in der Frage der Müttererwerbstätigkeit aus. Gemäß diesem Leitbild sollte die Mutter nicht erwerbstätig sein. Nach dem Kriegsopferversorgungsgesetz von 1950 wurden daher, wenn die Mutter eine Tätigkeit außer Haus aufnahm, sofort die Zahlungen reduziert. Die im Gesetz vorgesehene - unter diesem Aspekt kontraproduktive - Wiedereingliederung der Kriegsopfer, also auch der Witwen, in den Arbeitsmarkt kam nur halbherzig und mit jahrelanger Verzögerung in Gang. Grenzfälle wie beispielsweise Witwen, die während des Krieges geheiratet hatten und daher nie mit ihrem Ehemann zusammengelebt und in der Regel keine gemeinsamen Kinder hatten, wurden von der Versorgung weitgehend ausgeschlossen. ${ }^{37}$ Es ging offenbar weniger darum, Angehörige von Kriegsopfern zu versorgen, als darum, den gefallenen Vater in seiner Ernährerrolle zu ersetzen und Mutter und Kindern die Möglichkeit zu einem Familienleben mit klassischer Rollenverteilung zu geben. ${ }^{38}$ Trotz der restaurativen Bemühungen krankten diese Witwen-Familien jedoch in einem entscheidenden Punkt: Es war de facto kein Vater vorhanden.

Die Politik sah solche „Ehereste“ nicht als dauerhafte soziale Lebensform an. Sie galten als vorübergehendes Kriegsfolgeproblem, das sich mit der Zeit, wenn

35 Vgl. dazu Heineman, Complete Families; Moeller, Mütter.

36 Vgl. dazu Heineman, Complete Families; dies., Difference; dies., Single Women.

37 Heineman, Complete Families, S. 37-42.

38 Die Pensionen waren jedoch so niedrig, daß sie ohne Nebeneinkünfte nur ein Leben am äußersten Rande des Existenzminimums ermöglichten. 
neue Generationen nachgewachsen waren, von selbst erledigen würde. ${ }^{39}$ Ähnliches traf auch für ein weiteres Phänomen der Nachkriegszeit zu: die sogenannten „Onkelehen“. Um den privilegierten Status in der Kriegsopferversorgung nicht zu verlieren, verzichtete manche Kriegswitwe, die bereits in einer neuen eheähnlichen Gemeinschaft lebte, auf den Trauschein. ${ }^{40}$ Während in den ersten Jahren nach Kriegsende diese „Onkelehen“, die in den offiziellen Statistiken gar nicht faßbar sind, häufig eher den Charakter einer Notgemeinschaft hatten, bildeten sich in den fünfziger Jahren zunehmend dauerhafte Beziehungen ohne Trauschein. Mitte der fünfziger Jahre gab es schätzungsweise rund 100000 solcher Lebensgemeinschaften. ${ }^{41}$ Anfang der sechziger Jahre wurden diese "wilden Ehen “ allerdings wieder zum Randphänomen. Viele Paare konnten es sich nun leisten zu heiraten. Andere Beziehungen endeten mit Trennung oder Tod. Gerade die Lebenspartner, die aufgrund körperlicher Versehrtheit nicht arbeiten konnten und daher auf die staatlichen Pensionen angewiesen waren, diejenigen also, die keine formelle Ehe schlossen, um ihre Pensionsansprüche nicht zu verlieren, starben auch früher.

Im nachhinein stellt sich auch die Frage, warum es in der Nachkriegszeit nicht zu einem dauerhaft wirksamen Emanzipationsschub der Ehefrauen und Mütter $\mathrm{kam}$. Sie hatten für einen gewissen Zeitraum die Verantwortung für das Überleben der Familien ganz übernommen und vielfach den Unterhalt der Familie allein verdienen müssen. Folgte daraus nicht ein Emanzipationsimpuls, der die geschlechtsspezifische Rollenverteilung dauerhaft in Frage stellte? Es ist das Argument angeführt worden, diese Emanzipation habe gezwungenermaßen stattgefunden und sei daher nicht dauerhaft tragfähig gewesen. Helmut Schelsky spitzte diese These dahingehend $z u, d a ß$ die Ehefrauen und Mütter in der frühen Nachkriegszeit nicht wegen ihres individuellen Leistungs- und Selbstverwirklichungsstrebens, sondern aufgrund der wirtschaftlichen Notlage der Familien berufstätig gewesen seien. Die so motivierte Erwerbstätigkeit, so Schelsky, schwäche nicht die Familienstrukturen, sondern sei im Gegenteil ein Indiz für das starke Gruppenbewußtsein. ${ }^{42}$ Von der Frau werde ihre Erwerbstätigkeit „eher als ein durch die Notlage der Familie diktiertes Erfordernis, als ein Appell der Familie an ihr Gemeinschaftsbewußtsein empfunden, als daß sie darin eine Verwirklichung der emanzipatorischen Forderungen des, Rechtes der Frau auf ihre eigene Persönlichkeit und

39 Zitat in Zopfy, Haushalts- und Familienstatistik, S. 153, vgl. dazu auch Moeller, Mütter, S. 130.

$40 \mathrm{Vgl}$. Heineman, Complete Families, S. 49-54.

41 Vgl. Denkschrift der katholischen Bischöfe Deutschlands zu den Fragen der „Rentenkonkubinate" vom 25. 2. 1955, abgedruckt in: Fam RZ, 3 (1953), H. 2, S. 33 . Die katholische Kirche griff das Problem auf, um damit ihrer Forderung nach der Aufhebung der obligatorischen Zivilehe Nachdruck zu verleihen. Eine kirchliche Eheschließung sollte nicht durch die Bindung an eine Zivilehe, die zum Verlust der Versorgungsansprüche führte, verhindert werden. Erst nachdem die katholische Kirche einen Musterprozeß verlor, in dem ein bayerischer Pfarrer angeklagt war, die kirchliche Trauung eines Paares vollzogen zu haben, das nicht zivilrechtlich verheiratet war, kam diese Bewegung zu einem Ende. Ausschlaggebend hierfür war letztlich, daß die Rentenreform von 1957 die soziale Sicherung auf ein höheres Niveau hob. Vgl. dazu Kuller, Stiefkind, S. $306 \mathrm{f}$.

42 Schelsky, Gleichberechtigung, S. 129-131, folgende Zitate ebenda. 
auf ihre eigene Lebensgestaltung' (Russel) erblicken könnte“. Die Rolle der erwerbstätigen Frau sei von der emanzipatorischen Programmatik „besitzbürgerlich verkannt" worden, indem den Frauen fälschlich privatkapitalistische Interessen und der Wunsch nach ökonomischer Selbständigkeit unterstellt worden seien - eine Interpretation, die der Soziologe allerdings nicht durch empirische Daten untermauerte.

Willenbacher legt noch eine andere Deutung nahe:43 Demnach kam es in der unmittelbaren Nachkriegszeit zu einer Aufwertung des traditionellen Arbeitsbereiches der Hausfrau. Die Versorgung der Familienmitglieder mit Lebensmitteln und Wohnraum sowie die emotionale Stabilisierung gewannen an Bedeutung gegenüber der außerhäuslichen Erwerbstätigkeit, die die traditionelle Domäne des Ehemanns und Vaters war. So verstärkte sich zwar der Prozeß der Gleichberechtigung, aber nicht durch ein Aufbrechen der traditionellen Rollenverteilung, sondern im Gegenteil durch eine „Retraditionalisierung“ der Rolle der Frau. Angesichts dessen war der Weg zurück in traditionelle Rollenmuster in den fünfziger Jahren gar nicht so weit, wenngleich er für die Frauen mit einem Verlust an innerfamiliärer Autorität und Autonomie verbunden war.

Beide Interpretationen betonen die analytische Trennung zwischen der Gleichberechtigungsdebatte und der Frage der innerfamiliären Rollenverteilung. Sie folgen damit einem konservativen Ansatz, der den Weg zur Gleichberechtigung der Frauen nicht in einer Angleichung der Rollen, sondern in einer Aufwertung der geschlechtsspezifischen Frauenrolle sah. ${ }^{44}$ Gerade für die Deutung der unmittelbaren Nachkriegszeit erscheint der Ansatz fruchtbar. Unter dieser Perspektive wird leichter nachvollziehbar, warum die Gleichberechtigung der Geschlechter bereits in den Debatten um die Verfassungen der Länder und um das Grundgesetz ein wichtiges Thema war, während die praktische Umsetzung dieses Gebots in Form einer Angleichung der rechtlichen und sozialen Situation nur sehr langsam in Gang kam.

Der Weg in die „Krise der Familie“ in den sechziger Jabren: die Entwicklung von Ebeschließungen, Scheidungen und Geburten

Nach Kriegsende 1945 erwartete man für die Eheschließungen eine ähnliche Entwicklung wie nach dem ersten Weltkrieg: Damals war die im Krieg zurückgegangene Zahl der Eheschließungen 1918 wieder stark angestiegen, und zwar weit über den Vorkriegsstand hinaus. Man hatte sich den Heiratsboom damit erklärt, daß viele Heiraten während des Krieges aufgeschoben worden waren und sich nach Kriegsende eine Art „Nachholeffekt“ einstellte. Dieser war bis Mitte der zwanziger Jahre wieder abgeflaut und die Heiratsziffer hatte sich auf das Niveau der Vorkriegszeit eingependelt.

1945 zeigte sich bereits in den ersten Monaten nach Kriegsende, daß die Entwicklung diesmal anders verlaufen würde: ${ }^{45}$ Die Heiratszahlen stiegen nur gering-

43 Willenbacher, Zerrüttung, S. $606 \mathrm{f}$.

44 Ähnlich schon Bäumer, Frau.

45 Zum folgenden vgl. Niehuss, Sozialgeschichte, S. 919-923. 
fügig an. Insgesamt blieb die Heiratsziffer zwischen 1946 und 1951 relativ stabil bei rund zehn Heiraten je 1000 Einwohner. Zwei Faktoren trafen hier zusammen: Zum einen war der "Nachholbedarf“ nach 1945 nicht so stark wie 1918, weil die Soldaten im Zweiten Weltkrieg häufiger Heimaturlaub gehabt hatten, damit sie heiraten konnten, was sich auch in der Entwicklung der Heiratsziffer zwischen 1939 und 1945 spiegelt, die keinen so starken Einbruch wie zwischen 1915 und 1918 aufweist. Außerdem scheinen sich noch 1939, angesichts des Krieges, viele junge Leute zu einer frühzeitigen Heirat entschlossen zu haben. Hinzu kam, daß nach Kriegsende oft die Voraussetzungen für Eheschließungen fehlten: Viele Männer waren noch in Kriegsgefangenschaft, und die wirtschaftliche Notsituation dämpfte die Neigung zur Familiengründung.

Tabelle 1: Eheschließungen und Ehescheidungen im Bundesgebiet: 46

\begin{tabular}{|c|c|c|c|c|}
\hline Jahr & $\begin{array}{l}\text { Ehe- } \\
\text { schließungen }\end{array}$ & $\begin{array}{l}\text { je } 1000 \\
\text { Einwobner }\end{array}$ & $\begin{array}{l}\text { Ehe- } \\
\text { scheidungen }\end{array}$ & $\begin{array}{l}\text { je } 10000 \\
\text { Einwobner }\end{array}$ \\
\hline 1946 & 400399 & 8,8 & 48601 & 11,2 \\
\hline 1947 & 482193 & 10,1 & 76597 & 16,8 \\
\hline 1948 & 525160 & 10,7 & 87593 & 18,7 \\
\hline 1949 & 506199 & 10,2 & 80139 & 16,9 \\
\hline 1950 & 535708 & 10,7 & 84740 & 16,9 \\
\hline 1951 & 522946 & 10,3 & 64009 & 12,7 \\
\hline 1952 & 483358 & 9,5 & 57933 & 11,4 \\
\hline 1953 & 462101 & 9,0 & 53876 & 10,5 \\
\hline 1954 & 453168 & 8,7 & 50670 & 9,8 \\
\hline 1955 & 461818 & 8,8 & 48277 & 9,2 \\
\hline 1956 & 478352 & 9,0 & 46101 & 8,7 \\
\hline 1957 & 482590 & 9,0 & 46352 & 8,6 \\
\hline 1958 & 494110 & 9,1 & 48050 & 8,9 \\
\hline 1959 & 503981 & 9,2 & 48848 & 8,9 \\
\hline 1960 & 521445 & 9,4 & 48878 & 8,8 \\
\hline 1961 & 529901 & 9,4 & 49280 & 8,8 \\
\hline 1962 & 530640 & 9,3 & 49521 & 8,7 \\
\hline 1963 & 507644 & 8,8 & 50840 & 8,8 \\
\hline 1964 & 506182 & 8,7 & 55710 & 9,5 \\
\hline 1965 & 492128 & 8,3 & 58718 & 10,0 \\
\hline 1966 & 484562 & 8,1 & 58730 & 9,8 \\
\hline 1967 & 483101 & 8,1 & 62835 & 10,5 \\
\hline 1968 & 444150 & 7,4 & 65264 & 10,8 \\
\hline 1969 & 446586 & 7,3 & 72300 & 11,9 \\
\hline 1970 & 444510 & 7,3 & 76520 & 12,6 \\
\hline 1971 & 432030 & 7,0 & 80444 & 13,1 \\
\hline 1972 & 415132 & 6,7 & 86614 & 14,0 \\
\hline 1973 & 394603 & 6,4 & 90164 & 14,5 \\
\hline 1974 & 377265 & 6,1 & 98584 & 15,9 \\
\hline
\end{tabular}

46 Quelle: Statistische Jahrbücher der Bundesrepublik, $1955 \mathrm{ff}$. 
Nach einem leichten Rückgang Anfang der fünfziger Jahre blieben die Eheschließungen bis Anfang der sechziger Jahre bei einer Quote von etwa neun Hochzeiten auf 1000 Einwohner stehen. Diese Stagnation konnte als ein Einpendeln auf ein dauerhaft stabiles Niveau interpretiert werden. Um so alarmierender mußte die Tatsache wirken, daß ab 1963 die Eheschließungsquote stark abnahm und bis Mitte der siebziger Jahre um rund ein Drittel auf 6,1 Eheschließungen auf 1000 Einwohner sank. Der Befund erhielt noch ein besonderes Gewicht angesichts des gleichzeitigen Anstiegs der Scheidungszahlen. 1972 wurden erstmals mehr Ehen aufgelöst als geschlossen. ${ }^{47}$ Betrachtet man die Gesamtzahl der bestehenden Ehen, dann zeigt sich, daß es ab 1972 immer weniger Ehen in der Bundesrepublik gab, denn ab diesem Zeitpunkt fiel die Bilanz der Eheschließungen und -trennungen bis 1987 stets zu Ungunsten der Ehen aus.

Die auf die Gesamtbevölkerungszahl hochgerechneten Eheschließungsquoten eröffnen aber nur einen oberflächlichen Blick auf die Situation. Sie sind durch demographische Effekte verzerrt und dürfen daher nicht unreflektiert als "gesunkene Heiratsfreudigkeit" interpretiert werden. Dagegen spricht schon die Tatsache, daß sich im selben Zeitraum der Anteil der verheirateten Frauen erhöht hat: ${ }^{48}$ Kohortenspezifische Berechnungen zeigen, daß von den zwischen 1896 und 1900 geborenen Frauen nur 86 Prozent, von den 1931 bis 1935 geborenen jedoch 94 Prozent bis zu ihrem 50. Lebensjahr mindestens einmal geheiratet haben. Von den Frauen aus den Jahrgängen 1945-1950, die Ende der sechziger/Anfang der siebziger Jahre ins Erstheiratsalter kamen, heirateten ebenfalls fast 95 Prozent.

Der Rückgang der Eheschließungsquote in den sechziger Jahren war vor allem darauf zurückzuführen, daß jetzt die geburtenschwächeren Jahrgänge aus den letzten Kriegsjahren und den ersten Nachkriegsjahren ins Heiratsalter kamen. Berücksichtigt man bei den Eheschließungszahlen die demographischen Veränderungen der Bevölkerung, dann zeigt sich erst ab Anfang der siebziger Jahre ein Rückgang der Heiratsquote. ${ }^{49}$ Sein Umfang ist schwer zu quantifizieren, da sich

47 Vgl. Meyer/Schulze, Frauen, S. 169. Die Zahl der Eheauflösungen umfaßt dabei nicht nur die Scheidungen, sondern auch die Eheauflösungen durch Tod eines Ehepartners. In den Zahlen spiegelt sich daher auch der zunehmende gesellschaftliche Alterungsprozeß. Der zeitliche Querschnittsbefund muß zudem dahingehend relativiert werden, daß Scheidungen und Eheschließungen unterschiedliche Kohorten betrafen.

48 Vgl. Schubnell, Geburtenrückgang, S. 25; Nave-Herz, Kontinuität, S. 64. Zwischen den ersten beiden Generationen liegt jedoch ein beachtenswerter Einbruch, der sich wohl hauptsächlich durch die Kriegsfolgen und den anschließenden Frauenüberschuß bzw. Männermangel erklärt. Vgl. dazu die Daten bei Mayer, Krise, S. 94. Mayer führt den zwischenzeitlichen Einbruch auch auf die Möglichkeiten zur Schwangerschaftsverhütung zurück. Dadurch sei die Zahl der Ehen, die aufgrund einer ungewollten Schwangerschaft geschlossen wurden, zurückgegangen. Zur weiteren Entwicklung vgl. Zwischenbericht der Enquete-Kommission Demographischer Wandel - Herausforderungen unserer älter werdenden Gesellschaft an den einzelnen und die Politik, BT-Drs. 12/7876 vom 14.6. 1994, S. 64, Tabelle 32.

${ }^{49}$ Schwarz, Familienpolitik, S. 91-104. Schwarz' Berechnungen für die Beurteilung der „Heiratshäufigkeit" beruhen auf der „Verheiratetenquote“, d.h. wie viele Frauen und Männer eines Geburtsjahrgangs im Laufe der mittleren Lebensphase mindestens einmal 
gleichzeitig das Heiratsalter nach oben verschoben hat: Während in den sechziger Jahren das Alter der Eheschließenden, die zum ersten Mal heirateten, von durchschnittlich 24,8 auf 22,7 (Frauen) bzw. von 27,0 Jahren auf 25,3 Jahre (Männer) gesunken war, ${ }^{50}$ kehrte sich der Trend ab Anfang der siebziger Jahre um. Der Rückgang der Eheschließungszahlen Anfang der siebziger Jahre zeigt daher nicht unbedingt eine Verweigerung der Heirat, sondern vor allem ein Aufschieben. ${ }^{51}$ Da der Prozeß bis heute nicht abgeschlossen ist, können auch keine abschließenden Aussagen über das Ergebnis gemacht werden. Es ist aber wahrscheinlich, daß in den jüngeren Altersgruppen ein zunehmender Teil von Personen zeitlebens unverheiratet bleiben wird. ${ }^{52}$ Festzuhalten ist außerdem: Das seither steigende Heiratsalter von Männern und Frauen gilt als wichtiger Faktor der Veränderung innerfamiliärer Strukturen. Späte Heirat bedeutet nämlich, daß sich die Kinderphase verkürzt und die Familien in der Regel weniger Kinder haben. ${ }^{53}$

Im Gegensatz zu den Eheschließungszahlen, die zunächst unmittelbar nach Kriegsende keine einschneidenden Veränderungen zeigten, kam es bei den Ehescheidungen zu einem kurzfristigen, starken Anstieg. Auch wenn dies letztlich eine gesellschaftliche Randerscheinung blieb und offenbar nicht Ausdruck einer sich dauerhaft verändernden Ehemoral war, lohnt es sich, diese Scheidungswelle näher zu betrachten, denn die Scheidungen waren als typische Nachkriegsschicksale auch längerfristig von Bedeutung.

Die Scheidungen der ersten Nachkriegsjahre waren im Vergleich zur Vorkriegszeit und zur Phase ab den fünfziger Jahren in zweierlei Hinsicht ungewöhnlich: ${ }^{54}$ Zum ersten wurden unverhältnismäßig oft Frauen schuldig geschieden, meist weil sie in der jahrelangen Trennungszeit andere Partnerschaften eingegangen waren. Die hohen Scheidungszahlen wirkten sich also weit über das gewohnte Maß hinaus negativ für die Frauen aus. Schuldig oder teilschuldig gesprochen, standen sie häufig vor einer finanziellen Katastrophe. Sie hatten keine oder nur geringe Unterhaltsansprüche an den ehemaligen Ehemann. Außerdem verloren sie die vom Ehemann abhängigen Versorgungsmöglichkeiten. Zweitens wurde ein großer Teil der Scheidungen nach wenigen und meist getrennt verbrachten Ehejahren ein-

verheiratet waren. Bei dieser Berechnung wird auch das steigende Alter bei der ersten Eheschließung sichtbar.

50 Nave-Herz, Wandel, Tabelle S. 298.

51 Hettlage spricht in diesem Zusammenhang von einer „Eheverzögerung“. Hettlage/Wagner, Familienreport, S. 126-130. Man könnte auch das sinkende Heiratsalter der sechziger Jahre in einen Zusammenhang mit den rückläufigen Heiratszahlen bringen. Bei gleichbleibender Jahrgangsstärke hätte ein Sinken des Heiratsalters zu einem Anstieg der Eheschließungszahlen aufgrund "vorgezogener" Eheschließungen führen müssen. Das trat aber aufgrund der schwachen Jahrgangsbesetzungen nicht ein. In langfristiger Perspektive seit der Jahrhundertwende war das spätere Heiratsalter das „normale“. Vgl. dazu auch Schäfers, Wandel, S. $126 \mathrm{f}$. Unter diesem Gesichtspunkt erscheint nicht das steigende Heiratsalter seit den siebziger Jahren, sondern das Sinken in den sechziger Jahren als „Pfadabweichung “. Weniger die verzögerten Eheschließungen ab den siebziger Jahren sind dann das historisch außergewöhnliche, sondern die vorgezogenen Heiraten der sechziger Jahre.

52 Schwarz, Familienpolitik, S. 100.

53 Vgl. Mayer, Krise, S. 93.

54 Vgl. dazu Niehuss, Kontinuität, S. $323 \mathrm{f}$. 
gereicht, viele Paare ließen sich in ungewöhnlich jungem Alter scheiden, und es waren von den Scheidungen auch verhältnismäßig wenig Kinder betroffen. Die typische Aufeinanderfolge der weiblichen Lebensphasen wurde durch die frühen Scheidungen aus der Reihe gebracht.

Ein Blick auf die Lebensläufe von Frauen der Generation, die kurz vor oder im Krieg das traditionelle Heiratsalter erreicht hatten, zeigt, daß unterschiedlichste Partnerschaften, Wohnformen und Generationenbeziehungen ihr Leben durchzogen. Das traditionelle Schema der einmaligen Eheschließung und Familiengründung haben viele Frauen dieser Generation nicht realisieren können. ${ }^{55} \mathrm{Be}-$ trachtet man die Familienzyklen, beginnend mit dem kinderlosen Paar über die Elternphase bis zu dem Zeitraum, in dem die Kinder das Elternhaus wieder verlassen, dann zeigt sich, daß die typische Phasenabfolge durch den Krieg und seine Folgen erheblich an Verbindlichkeit eingebüßt hatte. Das Aufbrechen der traditionellen weiblichen Statusabfolge von Jungfrau, Ehefrau und Witwe, das bereits in der ersten Hälfte des 20. Jahrhunderts eingeleitet worden war, bildete einen nicht unerheblichen Wegbereiter für die sogenannte sexuelle Revolution gegen Ende der sechziger Jahre. ${ }^{56}$

Nach dem Höhepunkt im Jahr 1948 sank die nach Kriegsende kurzfristig stark angestiegene Zahl der Ehescheidungen bis 1957 wieder und stagnierte dann zunächst bei einer Quote von knapp 9 je 10000 Einwohner, ehe sie ab 1964 wieder stärker anzusteigen begann. Zu einem erheblichen Teil beruhte das auf demographischen Faktoren, vor allem auf der Aufeinanderfolge geburtenschwacher und geburtenstarker Jahrgänge. Die Entwicklung der Scheidungszahlen ist naturgemäß, mit einer gewissen Zeitverzögerung, auf die der Eheschließungen bezogen. ${ }^{57}$ Bis Ende der fünfziger Jahre kamen geburtenstarke Jahrgänge ins Heiratsalter. Damit stieg die Zahl der Eheschließungen infolge des demographisches Effektes, da die jüngere Altersgruppe nun mehr Personen umfaßte. Das zog wiederum, nach einem zeitlichen Abstand, auch einen entsprechenden Anstieg der absoluten Scheidungszahlen nach sich. Die geburtenschwachen Jahrgänge des Zweiten Weltkriegs kamen im Laufe der sechziger Jahre ins Heiratsalter. Entsprechend nahm die absolute Zahl der Eheschließungen ab, was sich rein rechnerisch ceteris paribus in einem Rückgang der Scheidungszahlen in der Statistik der siebziger Jahre hätte niederschlagen müssen. ${ }^{58}$ Als die absoluten Scheidungszahlen nicht sanken, sondern sogar stiegen, obwohl geburtenschwache Jahrgänge von ihnen betroffen waren, mußte dieser Befund doppelt schwer wiegen.

Erste Hinweise auf die Ursachen gibt auch hier wieder ein Blick auf die Scheidungsurteile, die am Beispiel Bayerns näher beleuchtet werden sollen. Der Anteil

55 Beipiele dazu bei Heineman, Difference, S. 3.

56 Vgl. dazu Heineman, Difference, S. 3.

57 Die Zeitspanne, nach der das statistisch höchste Scheidungsrisiko besteht, war nicht immer gleich, schwankte aber schwerpunktmäßig zwischen fünf und zehn Ehejahren. Erst am Ende des Untersuchungszeitraumes kristallisierte sich die 15jährige Ehedauer als ein weiterer Schwerpunkt heraus: Hier zeigte sich der „empty-nest“-Effekt (Kinder werden unabhängig, beruflicher Wiedereinstieg der Frau, Midlife-Krisen). Vgl. Hettlage/Wagner, Familienreport, S. 163.

58 Vgl. zu diesen Überlegungen Braun, Ehelösungen im Jahre 1970, S. 389. 
der Männer an den Scheidungsklagen hat hier seit 1947 kontinuierlich abgenommen. ${ }^{59} \mathrm{Daß}$ bis 1951 überwiegend Männer die Scheidung einreichten, kann teilweise an der traditionellen Rollenverteilung gelegen haben, die den Frauen die Initiative in Ehefragen absprach. Die „Scheidungsfreudigkeit“ der Männer mag anfangs auch durch ihre guten Chancen auf dem Heiratsmarkt beflügelt worden sein. Wichtiger für die geringe Aktivität der Frauen war aber wohl, daß schuldig gesprochene Frauen nach einer Scheidung in den meisten Fällen vor dem wirtschaftlichen Nichts standen. Dies verweist auf einen anderen Problemkreis, der aber eng mit dem Scheidungsrecht zusammenhängt: Auch die sozialstaatlichen Regelungen gingen nämlich vom Leitbild der auf Lebenszeit geschlossenen Ehe aus und schufen gemäß der innerfamiliären Rollenverteilung spezifische abgeleitete Versorgungsmöglichkeiten für Ehefrauen, die sich im Falle einer Scheidung sehr negativ für die Frau auswirken konnten. 60

Der steigende Anteil der Scheidungsklagen, die von Frauen eingereicht wurden, korrespondiert mit der Tatsache, daß immer weniger Frauen schuldig gesprochen wurden. Eine Interpretation dieser Daten läßt darauf schließen, daß Frauen offenbar zunehmend "scheidungsfreudiger" wurden, weil sie nicht mit einem Schuldspruch und der damit häufig verbundenen wirtschaftlichen Verschlechterung rechneten. 1947 lagen beispielsweise in Bayern die Anteile der Schuldsprüche gegen Männer und gegen Frauen noch relativ nah beieinander. Knapp ein Drittel (30,9 Prozent) der Männer und gut ein Viertel der Frauen (25,3 Prozent) wurden für schuldig befunden. Im Laufe der Jahre ist der Anteil der Schuldurteile gegen Frauen erheblich zurückgegangen, stagnierte zwischen 1952 und 1962 bei etwa 13-14 Prozent und stieg danach nur leicht an. Der Teil der Urteile, in denen Männer für schuldig erklärt wurden, hat sich dagegen bis 1962 auf über 55 Prozent fast verdoppelt. Bis 1970 ging er nur leicht zurück. Etwas zurückgegangen war der Anteil der Urteile, in denen beide Ehepartner schuldig gesprochen wurden (von 35 auf 24 Prozent). Bis Mitte der fünfziger Jahre gab es auch einen relativ großen Anteil von Urteilen, in denen keiner der Ehegatten für schuldig befunden wurde (10 bis 15 Prozent). Nach 1956 ging der Wert dann stark zurück. ${ }^{61}$

Ein Blick auf das Alter der Geschiedenen zeigt, daß der Anteil der 25- bis 40jährigen nach 1960 stark zunahm. Diesem Trend entspricht, daß ab 1950 - also zehn Jahre zuvor - das Heiratsalter gesunken war. Bei diesen sehr jung geschlossenen Ehen bestand offenbar ein erhöhtes Scheidungsrisiko. Zahlreiche weitere Korrelationen lassen sich finden: So hatten beispielsweise evangelische und konfessionell ungebundene Ehen ein höheres Scheidungsrisiko als katholische, am stabilsten erwiesen sich Ehen zwischen Partnern mit mittlerem Bildungsniveau, besonders gefährdet waren hingegen Ehen, in denen die Frau höher qualifiziert war als der Mann, kinderlose Ehen wurden häufiger geschieden als kinderreiche, um nur

59 Ebenda.

60 Vgl. zu diesem Argument Schwarzhaupt, Scheidung, S. 466 f; Niehuss, Strukturgeschichte, S. 103-106.

61 Braun, Ehelösungen im Jahre 1970, S. 389. 
einige Punkte herauszugreifen.62 Diese Ergebnisse bilden Korrelationen ab und verweisen dadurch meist lediglich auf dahinterstehende Faktoren wie die wirtschaftlichen Verhältnisse, die Möglichkeiten der Erwerbstätigkeit für Männer und Frauen, die Bildungssituation, aber auch das Wertesystem der Beteiligten. So läßt sich eine Reihe von gesellschaftlichen und individuellen Faktoren ausmachen, die die Entwicklung der Scheidungszahlen beeinflußte. ${ }^{63}$

Eine wichtige Rahmenbedingung für die Entwicklung der Ehescheidungen bildeten die Vorgaben des Familien- und insbesondere des Scheidungstechts. Das Ehegesetz von 1946, das maßgeblich von den Alliierten bestimmt worden war, hielt in der Frage der Ehescheidung noch prinzipiell an dem von den Nationalsozialisten ausgeweiteten Zerrüttungsprinzip fest. Vor allem seitens katholischer Kritiker wurde die Scheidungswelle nach Kriegsende zu einem nicht unerheblichen Teil auf dieses laxe Scheidungsrecht zurückgeführt. Hier sei ,in die alten nationalsozialistischen Schläuche neuer alliierter Wein gegossen " worden. ${ }^{64}$ In der Praxis setzte sich aber bald das Schuldprinzip durch, zunächst durch die Rechtsprechung befördert, schließlich in der Familienrechtsreform 1961 auch im Gesetzestext stärker verankert. ${ }^{65}$ Mit der Reform 1961 wurde die Ehescheidung in der Bundesrepublik erschwert, denn der "unschuldige“ Ehepartner hatte nun ein gröBeres Widerspruchsrecht und konnte die Scheidung verhindern. ${ }^{66}$ Das verschärfte Scheidungsrecht galt bis zur Eherechtsreform von 1976, die nach schweren Auseinandersetzungen das Verschuldensprinzip aufhob und das Scheitern der Ehe statt dessen als schicksalshaften Prozeß interpretierte. Allerdings war schon zuvor das Verschuldensprinzip zunehmend unterlaufen worden, indem die Scheidungswilligen Vorabsprachen trafen und sich dann nach fiktiven Gründen scheiden ließen. Kurz vor der Reform 1976 waren schätzungsweise 90 Prozent der Scheidungen solche "Konventionalscheidungen“, in denen vorher Absprachen getroffen worden waren, die nach dem Gesetz eigentlich verboten waren. ${ }^{67}$

Ein unmittelbarer Bezug zwischen der Entwicklung des Scheidungsrechts und dem Anstieg der Scheidungen am Anfang der siebziger Jahre scheint nicht bestanden zu haben, denn es gab zu dieser Zeit keine Reform der Gesetzeslage, die das Anschwellen der Scheidungszahlen erklären hätte können. ${ }^{68}$ Vielmehr spiegelten sich in den Konjunkturen des Schuldprinzips in den fünfziger und frühen sechziger Jahren und der sogenannten Konventionalscheidung in den sechziger Jahren gesellschaftliche Trends, die sich in der Praxis gerade gegen den bestehenden Gesetzestext durchsetzten.

62 Nave-Herz, Familie heute, S. 116.

63 Vgl. zum folgenden allgemein u. a. Kaufmann, Familie - Modernität; Nave-Herz, Scheidungsursachen; Diekmann/Klein, Bestimmungsgründe; Kopp, Scheidung; Beck/Hartmann, Wechselwirkung.

64 Moser, Ehescheidungs- und Ehetrennungsrecht, S. 18, zitiert nach Mikat, Zerrüttungsprinzip, S. 68.

65 Frevert, Frauen-Geschichte, S. 271. Vgl. dazu auch Zeidler, Zeitgeist.

66 Zur zeitgenössischen Begründung der Reform vgl. die historisch weit ausgreifende Abhandlung von Mikat, Zerrüttungsprinzip.

67 Simon, Leitbilder, S. 30.

68 Dies bestätigt auch Bernöster, Grundlagen, S. 88f. Dort auch weitere Literaturhinweise. 
In einem langfristigen Prozeß hat sich die gesellschaftliche Bedeutung der Ehescheidung verändert. Lange Zeit, bis weit in das 20. Jahrhundert hinein, wurde die Scheidung vor allem in einem normativen Kontext diskutiert. ${ }^{69}$ Traditionell galt bis ins späte 19. Jahrhundert eine Ehescheidung als moralische Verfehlung und war mit gesellschaftlichen Sanktionen versehen. Eine Entscheidung zur Trennung war zudem irreversibel. Beide Aspekte, die gesellschaftliche Sanktionierung und die Irreversibilität, wurden im Zuge des Modernisierungsprozesses in Frage gestellt. Zunehmend galt die Scheidung für eheliche Konflikte als eine legitime Lösungsmöglichkeit, die weder durch gesellschaftliche Sanktionen noch durch Therapien beantwortet werden mußte. Kaufmann wies zudem darauf hin, daß im Zuge der Individualisierung des Lebensverlaufs normative Bindungen schwächer geworden seien und damit auch der Entschluß zu einer Ehescheidung individuell getroffen werden könne und müsse. ${ }^{70}$

Auf der einen Seite lockerten sich also die gesellschaftlichen Zwänge, auf der anderen Seite entstanden neue Konfliktherde in den Familien: Äußere Faktoren forderten zunehmend eine Flexibilität der familiären Strukturen. War beispielsweise auch die Ehefrau erwerbstätig, dann mußte das Familienleben nicht mehr nur um einen, sondern um zwei externe Arbeitsrhythmen herum organisiert werden. Mit der Durchsetzung des partnerschaftlichen Leitbildes in der Ehe war die Familienarbeit nicht mehr durch die traditionelle Rollenzuweisung bestimmten Personen zugeteilt, vielmehr mußte ihre Verteilung ausgehandelt werden. Ein anderer Prozeß, dessen Zusammenhang mit der Zunahme der Scheidungen allerdings nicht unumstritten ist, ist der Wertewandel. Die Selbstverwirklichung gewann demnach an Bedeutung, während Pflichtwerte an Wichtigkeit verloren. ${ }^{71}$ Einzelne Familienmitglieder - vornehmlich Ehefrauen und Mütter - forderten ihre Selbstverwirklichung zunehmend stärker ein und stellten dadurch die innerfamiliäre Solidarität auf eine harte Probe.

Vielfach wurde der Anstieg der Scheidungszahlen auch als Indiz für einen „Verfall der Familie" gedeutet. Neuere Forschungen argumentieren hingegen gerade umgekehrt: Die Ehe sei nicht von "Sinnverlust" bedroht, sondern im Gegenteil von einer Art „Sinnüberfrachtung" und idealisierten Vorstellungen von der emotionalen Qualität der Ehe. ${ }^{72}$ Die Funktion der Familie reduziere sich zunehmend auf die Befriedigung emotionaler Bedürfnisse, während wirtschaftliche Aspekte in den Hintergrund träten. Tatsächlich hat die Ehe viele ihrer traditionellen wirtschaftlichen und gesellschaftlichen Funktionen verloren. Sie ist immer weniger „zwingende Notwendigkeit zur Erfüllung bestimmter elementarer Bedürfnisse (z. B. Legitimation einer sexuellen Beziehung) " und „materielle Versorgungsinstitution (vor allem für Frauen) ${ }^{\prime}{ }^{73}$ Die Anforderungen an die Ehe und die idealisier-

69 Vgl. Nave-Herz, Scheidungsursachen, S. 35-46.

70 Kaufmann, Familie - Modernität. Vgl. auch Nave-Herz, Scheidungsursachen, S. 37.

71 Vgl. dazu Klages, Wertorientierungen; Inglehart, Umbruch; vgl. auch zum Wertewandel als Ursache für die Zunahme der Scheidungen die empirische Studie von Scheller, Wertewandel, S. $68 \mathrm{f}$.

72 Vgl. Nave-Herz, Familiale Veränderungen.

73 Nave-Herz, Scheidungsursachen, S. 41. 
ten Hoffnungen auf emotionale Erfüllung haben sich dabei gleichzeitig erhöht, denn sie sind zum dominanten Inhalt der Ehe geworden. ${ }^{74}$ Die späten sechziger Jahre bilden eine Umbruchphase, in der aus der neuen Sichtweise von Ehe und Scheidung zunehmend praktische Konsequenzen gezogen wurden.

Bereits 1955 beklagte der erste Familienminister der Bundesrepublik, FranzJosef Wuermeling, den massiven "Geburtenschwund“, der in seinen Augen gemeinsam mit dem Rückgang der Sterblichkeit zu einem „Verfall des Volkskörpers" durch Überalterung führen werde. ${ }^{75}$ Schon lange vor dem sogenannten „Pillenknick“, dem dramatischen Geburtenrückgang in den sechziger Jahren, war Wuermeling von der demographischen Entwicklung in Westdeutschland beunruhigt, die heute als erster demographischer Übergang bezeichnet wird. ${ }^{76}$ Diese Theorie erklärt den allgemeinen Rückgang der Geburten als zeitlich verzögerte Anpassung der Kinderzahl an die stark gesunkene Säuglings- und Kindersterblichkeit. Durch den medizinischen Fortschritt überlebten allerdings nicht nur mehr Kinder, auch die allgemeine Lebenserwartung erhöhte sich. Der Eindruck einer Überalterung der Bevölkerung wurde vor allem durch eine immer höhere Lebenserwartung der alten Menschen hervorgerufen und nicht so sehr durch die sinkende Kinderzahl.

Der erste demographische Übergang war ein langfristiger Prozeß, der schon lange zuvor eingesetzt hatte. Die Statistik zeigt bereits seit der Jahrhundertwende einen Rückgang der Geburtenzahlen. Auf 1000 Einwohner kamen 1900 im Deutschen Reich rund 36 Lebendgeborene, bis 1975 sank diese Zahl - mit kleinen Gegenbewegungen Anfang der zwanziger Jahre und Ende der dreißiger Jahre auf rund zehn (in der Bundesrepublik). ${ }^{77}$ Die Entwicklung vollzog sich nicht in allen Regionen Deutschlands gleichmäßig. In Bayern beispielsweise lagen die Werte insgesamt etwas über dem Reichs- bzw. Bundesdurchschnitt (1900: 36,7; 1975: 11,1), ${ }^{78}$ was vor allem mit der agrarischen Struktur des Landes und den generell höheren Kinderzahlen in bäuerlichen Familien in Zusammenhang gebracht wird.

$\mathrm{Ab}$ Anfang der fünfziger Jahre war die allgemeine Geburtenquote in der Bundesrepublik gleichbleibend hoch. Auch als Anfang der sechziger Jahre weniger Ehen geschlossen wurden, blieb die Geburtenquote bis Mitte der sechziger Jahre relativ stabil bei etwa 17 Geburten auf 1000 Einwohner. Diese Phase wurde als

74 Meyer/Schulze, Frauen, S. 172.

75 Der Familienlastenausgleich - Erwägungen zur gesetzgeberischen Verwirklichung. Denkschrift des Bundesministers für Familienfragen, Bonn November 1955, S. 3-4, BAK, B 136/6134. Dabei ist zu bedenken, daß die Überalterung des „wirtschaftlichen Tragkörpers“, gemeint war damit die Gruppe der erwerbstätigen Personen, nach 1945 nicht nur auf natürlichen demographischen Prozessen beruhte, sondern in erheblichem Maß auf die Kriegsverluste, die vor allem die 18 - bis 43 jährigen Männer betroffen hatten, zurückzuführen war. Castell, Konsequenzen, S. 121.

$76 \mathrm{Vgl}$. Schubnell, Geburtenrückgang, S. 11. Zur frühen Interpretation des demographischen Übergangs vgl. u. a. Mackenroth, Bevölkerungslehre. Vgl. dazu auch Birg u. a., Bevölkerungsrückgang.

77 Hubbard, Familiengeschichte, S. 93.

78 Ebenda. 
Tabelle 2: Lebendgeborene in der Bundesrepublik:79

\begin{tabular}{|c|c|c|c|}
\hline Jahr & absolute Zahl & $\begin{array}{l}\text { je } 1000 \\
\text { Einwobner }\end{array}$ & $\begin{array}{l}\text { Darunter } \\
\text { unebeliche } \\
\text { Geburten } \\
\text { (in Prozent) }\end{array}$ \\
\hline 1946 & 732998 & 16,1 & 16,4 \\
\hline 1947 & 781421 & 16,4 & 11,9 \\
\hline 1948 & 806074 & 16,5 & 10,2 \\
\hline 1949 & 832803 & 16,8 & 9,3 \\
\hline 1950 & 812835 & 16,2 & 9,7 \\
\hline 1951 & 795608 & 15,7 & 9,6 \\
\hline 1952 & 799080 & 15,7 & 9,0 \\
\hline 1953 & 796096 & 15,5 & 8,7 \\
\hline 1954 & 816028 & 15,7 & 8,4 \\
\hline 1955 & 820128 & 15,7 & 7,9 \\
\hline 1956 & 855887 & 16,1 & 7,5 \\
\hline 1957 & 892228 & 16,6 & 7,2 \\
\hline 1958 & 904465 & 16,7 & 6,9 \\
\hline 1959 & 951942 & 17,3 & 6,7 \\
\hline 1960 & 968629 & 17,4 & 6,3 \\
\hline 1961 & 1012687 & 18,0 & 6,0 \\
\hline 1962 & 1018552 & 17,9 & 5,6 \\
\hline 1963 & 1054123 & 18,3 & 5,2 \\
\hline 1964 & 1065437 & 18,2 & 5,0 \\
\hline 1965 & 1044328 & 17,7 & 4,7 \\
\hline 1966 & 1050345 & 17,6 & 4,6 \\
\hline 1967 & 1019459 & 17,0 & 4,6 \\
\hline 1968 & 969825 & 16,1 & 4,8 \\
\hline 1969 & 903456 & 14,8 & 5,0 \\
\hline 1970 & 810808 & 13,4 & 5,5 \\
\hline 1971 & 778526 & 12,7 & 5,8 \\
\hline 1972 & 701214 & 11,3 & 6,1 \\
\hline 1973 & 635633 & 10,3 & 6,3 \\
\hline 1974 & 626373 & 10,1 & 6,3 \\
\hline
\end{tabular}

„Babyboom" interpretiert, denn in der Zusammenschau beider Trends hatten die einzelnen Familien mehr Kinder als zuvor. Das zeigen auch demographisch bereinigte Zahlen: Betrug 1950 die zusammengefaßte Geburtenziffer pro Frau 2,10 Kinder, so stieg sie bis 1965 auf 2,51.80 Damit war ein Wert erreicht, der dem der Jahre unmittelbar vor dem Ersten Weltkrieg entsprach.

79 Quelle: Statistische Jahrbücher der Bundesrepublik, $1955 \mathrm{ff}$.

80 Schwarz, Familienpolitik, S. 113. Die zusammengefaßte Geburtenziffer (total fertility rate TFR) gibt an, wie viele Kinder eine (fiktive) Frauengeneration im Laufe ihres Lebens zur Welt bringt, wenn keine Frau vor dem 50. Lebensjahr stirbt und bis dahin die altersspezifischen Geburtenhäufigkeiten des Beobachtungsjahres weitergelten. Die TFR wird aus der Summe der alters- bzw. kohortenspezifischen Geburtenziffer eines Kalenderjahres berechnet. Mit dieser Berechnungsmethode werden demographische Effekte geburtenschwacher und -starker Jahrgänge ausgeschaltet. 
Seit Mitte der sechziger Jahre registrierten die Statistiker bundesweit aber einen alarmierenden Rückgang der Geburtenzahlen, der so stark ausfiel, daß er nicht mehr allein durch die Zusammensetzung der Elternjahrgänge erklärt werden konnte. Nach den Berechnungen, die der Direktor des Bundesinstituts für Bevölkerungsforschung Hermann Schubnell 1972 im Auftrag des Bundesfamilienministeriums durchführte, ließ sich der Mitte der sechziger Jahre einsetzende Geburtenrückgang nur zu einem Fünftel auf Änderungen der Altersstruktur zurückführen, vier Fünftel dagegen seien "echte “ Abnahme. ${ }^{81}$ Um dieses Phänomen sichtbar zu machen, muß man wieder die zusammengefaßte Geburtenziffer heranziehen, die das statistische Maß für die „echte“ Abnahme der Geburten darstellt. Diese Geburtenziffer weist ab 1968/1970 einen massiven Einbruch auf. 82

In den Bundesländern gab es in den Geburtenziffern recht große Unterschiede. Schon das Ausgangsniveau der einzelnen Länder wies 1951 erhebliche Differenzen auf. Spitzenreiter war das Saarland, gefolgt von Niedersachsen und Rheinland-Pfalz. Bayern nahm eine mittlere Position ein. Am Ende der Liste finden sich die Stadtstaaten, vor allem Berlin, wo die Geburtenziffer um ein Drittel niedriger war als in Rheinland-Pfalz. Der Anstieg bis Mitte der sechziger Jahre war dann etwa parallel verlaufen (b), nur Rheinland-Pfalz hatte seine Spitzenposition verloren. ${ }^{83}$ Der anschließende Rückgang bis Mitte der siebziger Jahre zeigte wieder etwa parallele Entwicklungslinien. Mitte der achtziger Jahre hatte sich die Geburtenziffer in den Bundesländern - mit Ausnahme der Stadtstaaten - gegenüber 1965 etwa halbiert (c). Die Dynamik der Veränderung der Geburtenziffer war also im Bundesgebiet ähnlich. Das unterschiedliche Niveau von 1950 hatte sich dadurch perpetuiert.

Eine weitere Maßzahl, die Auskunft über den Geburtenrückgang gibt, ist die der Kinderzahl pro Familie. Hatten um die Jahrhundertwende noch über die Hälfte aller Familien im Deutschen Reich vier oder mehr Kinder, so war ihr Anteil Anfang der siebziger Jahre auf unter vier Prozent gesunken. Die durchschnittliche Kinderzahl pro Ehe lag 1971 bei 1,5 Kindern. ${ }^{84}$ Dieser Wert suggeriert zunächst einen allgemeinen Rückgang der Familiengröße. Tatsächlich errechnete er sich aber fast ausschließlich durch die Abnahme der 4- und Mehrkinderfamilien. ${ }^{85}$ Die statistischen Daten waren nicht mehr so weit gestreut. Der Prozeß ist also vielleicht genauer mit dem Begriff der Konzentration zu fassen. Zwischen den Eheschließungskohorten 1950/54 und 1955/59 kann man in nahezu allen gesellschaftlichen Schichten einen sprunghaft ansteigenden Trend zur "Zweikinderfamilie“ beobachten, während sowohl die größeren Familien als auch kinderlose und „Ein-

81 Schubnell, Geburtenrückgang, S. $26 \mathrm{f}$.

82 Da die Statistik in 5-Jahres-Schritten arbeitet, tritt das Phänomen erst 1970 auf, bei durchgehender Zählung zeigen sich bereits spätestens ab 1968 einschneidende Veränderungen.

$83 \mathrm{Vgl}$. Tabelle 3. Die Entwicklung im Saarland verzeichnete einen außergewöhnlichen Geburteneinbruch, der aber im Hinblick auf die besondere politische Entwicklung getrennt zu untersuchen wäre.

84 Hubbard, Familiengeschichte, S. 101.

85 Vgl. dazu Niehuss, Strukturgeschichte, S. 352 f. Wie in vielen familienstatistischen Fragen scheint auch in diesem Fall der Median (häufigster Wert) als statistische Größe besser geeignet als das statistische Mittel. 
Tabelle 3: ' 'usammengefaßte Geburtenziffer (TFR) je 1000 Frauen bis zum Alter von $49 \mathrm{Jah}-$ ren 1951-1985 nach Bundesländern:86

\begin{tabular}{|c|c|c|c|c|c|c|c|c|c|}
\hline Land & $\begin{array}{l}a=\text { TFR } \\
b=\text { Proz. } \\
\text { v. } a(1951) \\
c=\text { Proz. } \\
\text { v. a }(1965)\end{array}$ & 1951 & 1955 & 1960 & 1965 & 1970 & 1975 & 1980 & 1985 \\
\hline $\begin{array}{l}\text { Schlesw.- } \\
\text { Holst. }\end{array}$ & $\begin{array}{l}\mathbf{a} \\
\mathbf{b} \\
\mathbf{c}\end{array}$ & $\begin{array}{r}2141 \\
100\end{array}$ & $\begin{array}{r}2121 \\
99\end{array}$ & $\begin{array}{l}2434 \\
114\end{array}$ & $\begin{array}{r}2645 \\
124 \\
100\end{array}$ & $\begin{array}{r}2123 \\
99 \\
80\end{array}$ & $\begin{array}{r}1483 \\
69 \\
56\end{array}$ & $\begin{array}{r}1449 \\
68 \\
55\end{array}$ & $\begin{array}{r}1243 \\
58 \\
47\end{array}$ \\
\hline Hamburg & $\begin{array}{l}a \\
b \\
c\end{array}$ & $\begin{array}{r}1554 \\
100\end{array}$ & $\begin{array}{r}1508 \\
97\end{array}$ & $\begin{array}{r}1807 \\
116\end{array}$ & $\begin{array}{r}1948 \\
125 \\
100\end{array}$ & $\begin{array}{r}1483 \\
95 \\
76\end{array}$ & $\begin{array}{r}1164 \\
75 \\
60\end{array}$ & $\begin{array}{r}1226 \\
79 \\
63\end{array}$ & $\begin{array}{r}1101 \\
71 \\
57\end{array}$ \\
\hline Nieders. & $\begin{array}{l}a \\
b \\
c\end{array}$ & $\begin{array}{r}2236 \\
100\end{array}$ & $\begin{array}{r}2213 \\
99\end{array}$ & $\begin{array}{r}2511 \\
112\end{array}$ & $\begin{array}{r}2749 \\
123 \\
100\end{array}$ & $\begin{array}{r}2280 \\
102 \\
83\end{array}$ & $\begin{array}{r}1570 \\
70 \\
57\end{array}$ & $\begin{array}{r}1497 \\
67 \\
55\end{array}$ & $\begin{array}{r}1286 \\
58 \\
47\end{array}$ \\
\hline Bremen & $\begin{array}{l}a \\
b \\
c\end{array}$ & $\begin{array}{r}1779 \\
100\end{array}$ & $\begin{array}{r}1800 \\
101\end{array}$ & $\begin{array}{r}2057 \\
116\end{array}$ & $\begin{array}{r}2300 \\
129 \\
100\end{array}$ & $\begin{array}{r}1772 \\
100 \\
77\end{array}$ & $\begin{array}{r}1353 \\
76 \\
59\end{array}$ & $\begin{array}{r}1248 \\
72 \\
54\end{array}$ & $\begin{array}{r}1084 \\
61 \\
47\end{array}$ \\
\hline $\begin{array}{l}\text { Nordrh.- } \\
\text { Westf. }\end{array}$ & $\begin{array}{l}a \\
b \\
c\end{array}$ & $\begin{array}{c}2054^{*} \\
100\end{array}$ & $\begin{array}{r}2135 \\
104\end{array}$ & $\begin{array}{r}2340 \\
114\end{array}$ & $\begin{array}{r}2473 \\
120 \\
100\end{array}$ & $\begin{array}{r}1963 \\
96 \\
79\end{array}$ & $\begin{array}{r}1434 \\
70 \\
58\end{array}$ & $\begin{array}{r}1425 \\
69 \\
58\end{array}$ & $\begin{array}{r}1272 \\
62 \\
51\end{array}$ \\
\hline Hessen & $\begin{array}{l}a \\
b \\
c\end{array}$ & $\begin{array}{r}2012 \\
100\end{array}$ & $\begin{array}{r}2012 \\
100\end{array}$ & $\begin{array}{r}2295 \\
114\end{array}$ & $\begin{array}{r}2413 \\
120 \\
100\end{array}$ & $\begin{array}{r}1898 \\
94 \\
79\end{array}$ & $\begin{array}{r}1388 \\
69 \\
58\end{array}$ & $\begin{array}{r}1362 \\
68 \\
56\end{array}$ & $\begin{array}{r}1188 \\
59 \\
49\end{array}$ \\
\hline Rheinl.-Pf. & $\begin{array}{l}a \\
b \\
c\end{array}$ & $\begin{array}{c}2397^{*} \\
100\end{array}$ & $\begin{array}{r}2471 \\
103\end{array}$ & $\begin{array}{r}2608 \\
109\end{array}$ & $\begin{array}{r}2715 \\
113 \\
100\end{array}$ & $\begin{array}{r}2133 \\
89 \\
79\end{array}$ & $\begin{array}{r}1453 \\
61 \\
54\end{array}$ & $\begin{array}{r}1486 \\
62 \\
55\end{array}$ & $\begin{array}{r}1286 \\
54 \\
47\end{array}$ \\
\hline Baden-W. & $\begin{array}{l}a \\
b \\
c\end{array}$ & $\begin{array}{r}2108 \\
100\end{array}$ & $\begin{array}{r}2215 \\
105\end{array}$ & $\begin{array}{r}2474 \\
117\end{array}$ & $\begin{array}{r}2601 \\
123 \\
100\end{array}$ & $\begin{array}{r}2064 \\
98 \\
79\end{array}$ & $\begin{array}{r}1515 \\
72 \\
58\end{array}$ & $\begin{array}{r}1508 \\
72 \\
58\end{array}$ & $\begin{array}{r}1323 \\
63 \\
51\end{array}$ \\
\hline Bayern & $\begin{array}{l}a \\
b \\
c\end{array}$ & $\begin{array}{c}2084^{* *} \\
100\end{array}$ & $\begin{array}{r}2144 \\
103\end{array}$ & $\begin{array}{r}2462 \\
118\end{array}$ & $\begin{array}{r}2537 \\
122 \\
100\end{array}$ & $\begin{array}{r}2006 \\
96 \\
79\end{array}$ & $\begin{array}{c}1470 \\
71 \\
58\end{array}$ & $\begin{array}{r}1484 \\
71 \\
59\end{array}$ & $\begin{array}{r}1335 \\
64 \\
53\end{array}$ \\
\hline Saarland & $\begin{array}{l}a \\
b \\
c\end{array}$ & $\begin{array}{c}2465^{*} \\
100\end{array}$ & $\begin{array}{r}2383 \\
97\end{array}$ & $\begin{array}{r}2571 \\
104\end{array}$ & $\begin{array}{r}2581 \\
105 \\
100\end{array}$ & $\begin{array}{r}1820 \\
74 \\
71\end{array}$ & $\begin{array}{r}1302 \\
53 \\
50\end{array}$ & $\begin{array}{r}1360 \\
55 \\
53\end{array}$ & $\begin{array}{r}1190 \\
48 \\
46\end{array}$ \\
\hline $\operatorname{Berlin}(W)$ & $\begin{array}{l}a \\
b \\
c\end{array}$ & $\begin{array}{r}1509 \\
100\end{array}$ & $\begin{array}{r}1329 \\
88\end{array}$ & $\begin{array}{r}1514 \\
100\end{array}$ & $\begin{array}{r}1795 \\
119 \\
100\end{array}$ & $\begin{array}{r}1453 \\
96 \\
81\end{array}$ & $\begin{array}{r}1336 \\
89 \\
74\end{array}$ & $\begin{array}{r}1518 \\
101 \\
85\end{array}$ & $\begin{array}{r}1407 \\
93 \\
78\end{array}$ \\
\hline $\begin{array}{l}\text { Bundes- } \\
\text { gebiet }\end{array}$ & $\begin{array}{l}a \\
b \\
c\end{array}$ & $\begin{array}{r}2062 \\
100\end{array}$ & $\begin{array}{r}2113 \\
102\end{array}$ & $\begin{array}{r}2371 \\
115\end{array}$ & $\begin{array}{r}2508 \\
122 \\
100\end{array}$ & $\begin{array}{r}1992 \\
97 \\
79\end{array}$ & $\begin{array}{r}1452 \\
70 \\
58\end{array}$ & $\begin{array}{r}1449 \\
70 \\
58\end{array}$ & $\begin{array}{r}1281 \\
62 \\
51\end{array}$ \\
\hline
\end{tabular}

$\because 1952$

$* 1953$

${ }_{86}$ Quelle: Übersicht 3/23 bei Schwarz, Familienpolitik, S. 146, und eigene Berechnungen. 
kindfamilien " seltener wurden. ${ }^{87}$ Eine Ausnahme bildeten lediglich die Landwirte mit traditionell hoher Kinderzahl und die kleinen Selbständigen und einfachen Angestellten mit unterdurchschnittlicher Kinderzahl. Der Unterschied zwischen Stadt und Land hat sich im Laufe der sechziger Jahre zunehmend eingeebnet. ${ }^{88}$

Die Ergebnisse aus den statistischen Erhebungen 1961 und 1970 legen den Schluß nahe, daß die Familien damit auf eine gleichzeitig spürbare wirtschaftliche Aufwärtsentwicklung reagierten. ${ }^{89}$ Diese Korrelation scheint die zeitgenössische Einschätzung der Entwicklung der Geburtlichkeit zu bestätigen, die davon ausging, daß sich nach Kriegsende im Vergleich zur Situation vor 1945 eine grundlegende Änderung vollzogen habe: Ärmere Familien hatten nun weniger Kinder als wohlhabendere. Das Einkommen schien direkten - und nicht mehr gegenläufigen - Einfluß auf die Kinderzahl der Familien zu haben. Mit dieser direkten Relation zwischen Einkommen und Kinderzahl legitimierten die Familienpolitiker der frühen Bundesrepublik auch den materiellen Ansatz ihrer Politik: Edo Osterloh, Stellvertreter des Bundesfamilienministers, erklärte beispielsweise im Oktober 1954: „Die moderne Familie wünscht nicht mehr Kinder, als sie nach ihrem jeweiligen Lebensstandard auch einigermaßen standesgemäß aufziehen kann. In den verschiedenen Bevölkerungsschichten steht die Kinderzahl heute in direkter Beziehung zum Einkommen. Vor einigen Jahrzehnten war es noch umgekehrt; damals hatten die Reicheren gewöhnlich weniger, die Ärmeren dagegen mehr Kinder; heute jedoch hat der gutverdienende ungelernte Arbeiter im Durchschnitt weniger Kinder als der gutverdienende gelernte; ebenso ist es auch bei den Angestellten und Beamten (mit Ausnahme der Spitzenverdiener, die traditionell kinderarm sind). $"{ }^{\circ 0}$ Monokausal darf diese Beobachtung der Relation zwischen Einkommen und Kinderzahl jedoch nicht interpretiert werden. Hinzu kommen neben den wirtschaftlichen auch viele gesellschaftliche Aspekte. Aber weder diese noch Faktoren wie Ortsgröße, konfessionelle Einflüsse und das Heiratsalter der Frauen, die alle die Kinderzahl beeinflussen, können das Phänomen des Geburtenrückgangs ganz erklären.91

Im „Babyboom“ der frühen sechziger Jahre trafen mehrere Entwicklungen zusammen, die in ihrer kumulativen Wirkung die Geburtenziffer kurzfristig nach oben verschoben. ${ }^{92}$ So war Anfang der sechziger Jahre das Heiratsalter und parallel dazu auch das Alter der Frauen bei ihrer ersten Geburt gesunken. Diese „vorgezogenen " Geburten summierten sich zu den Geburten der älteren Frauen hinzu. Gleichzeitig wurde manche aufgeschobene Familiengründung nun, da sich die wirtschaftliche Lage verbessert hatte, nachgeholt. Hinzu kam, daß viele Familien, die bereits in den fünfziger Jahren den Entschluß gefaßt hatten, keine Kinder mehr auf die Welt zu bringen, sich angesichts der zunehmend konsolidierten öko-

87 Niehuss, Strukturgeschichte, S. 356, $367 \mathrm{f}$.

88 Schubnell, Geburtenrückgang, S. $28 \mathrm{f}$.

89 Niehuss, Strukturgeschichte, S. 368.

90 Osterloh, Familienpolitik, Zitat S. 698. Statistisch wurde die These von Karl Schwarz im Rahmen der Mikrozensuserhebung von 1962 untermauert: Schwarz, Kinderzahlen.

91 Niehuss, Strukturgeschichte, S. $371 \mathrm{f}$.

92 Vgl. zum folgenden Korte, Bevölkerungsstruktur; Niehuss, Strukturgeschichte, S. 376 f., Bernöster, Grundlagen, S. 63-67. 
nomischen Situation noch spät für ein weiteres Kind entschieden. Schließlich kam Anfang der sechziger Jahre die geburtenstarke Kohorte der in den dreißiger Jahren geborenen Frauen und Männer ins Eltern-Alter. Obwohl jede einzelne Frau durchschnittlich immer weniger Schwangerschaften hatte, stieg die Geburtenziffer, weil nun wieder mehr Frauen im fruchtbaren Alter waren. ${ }^{93}$

Im Lichte dieser Faktoren erscheint die Stabilisierungsphase der sechziger Jahre, die zeitgenössisch als Ende des demographischen Übergangs angesehen wurde, als eine künstliche Stagnation, die das weitere Absinken der Geburten nur zeitweilig unterbrach. ${ }^{94}$ Als 1968 ein massiver Geburteneinbruch - der sogenannte Pillenknick - auftrat, interpretierten die Zeitgenossen dies als eine neue Phase der Bevölkerungsentwicklung. Er kann jedoch zu einem Teil als ein Wiedereinschwenken auf die langfristige Entwicklungslinie gedeutet werden. Ganz läßt sich der Rückgang ab Ende der sechziger Jahre aber nicht auf eine bloße Fortsetzung des ersten demographischen Übergangs reduzieren, denn die Geburtenzahl sank noch einmal stärker und weit unter einen bevölkerungsstatistisch stabilen Wert von 2,1 Geburten pro Frau, der theoretisch den Endpunkt des ersten demographischen Übergangs hätte bilden sollen. Er markiert daher den Beginn eines zweiten demographischen Übergangs.

Kohortenspezifische Untersuchungen haben gezeigt, daß das Phänomen des zweiten Geburtenrückgangs durch Generationeneffekte verursacht war, jedoch nicht im einfachen Sinne des Übergangs von einer Generation zu einer anderen. Vielmehr war der Geburtenrückgang Ende der sechziger Jahre gekennzeichnet durch das Zusammentreffen mehrerer Generationeneffekte, die aus verschiedenen wirtschaftlichen und politischen Rahmenbedingungen resultierten und kumulativ zusammenwirkten. ${ }^{95}$ Die Frauengruppe, die um 1939 geboren war, entschied sich zu dieser Zeit immer seltener für die Geburt eines dritten Kindes. Gleichzeitig brachte die nächstjüngere Frauenkohorte der um 1946 Geborenen seltener ein zweites Kind zur Welt. Ebenfalls kohortenspezifisch verringerte sich auch die Zahl der Frauen, die ein viertes Kind gebaren. Dieses Zusammentreffen der Kohorteneffekte trug maßgeblich zum Einbruch der Geburten zwischen 1966 bis 1972 bei. 96 Durch das Zusammentreffen verschiedener Generationeneffekte entstand zeitgenössisch der Eindruck, es handle sich um einen "historischen Effekt", einen Prozeß, der durch ein Ereignis ausgelöst worden sei, das die Frauen verschiedener Altersstufen gleichzeitig betroffen hätte. Der zweite demographische Übergang wurde im Volksmund daher schnell als „Pillenknick“ tituliert.97

93 Nach dem Kriegsende 1945 hatte der Zuzug von Vertriebenen und Flüchtlingen einen ähnlichen Effekt gehabt. In Vertriebenenehen gab es durchschnittlich weniger Kinder als in Ehen der einheimischen Bevölkerung. Gleichzeitig waren jedoch die Neubürger-Familien durchschnittlich jünger als die allgemeine Bevölkerung Bayerns. Daher war ihr Anteil an der Geburtenzahl immer noch relativ hoch, obwohl die mittlere Kinderzahl pro Ehe unter dem Durchschnitt lag. Vgl. Rother, Bevölkerungsbewegung, S. 279-281.

94 Korte, Bevölkerungsstruktur, S. 18.

95 Niehuss, Strukturgeschichte, S. $375 \mathrm{f}$.

$96 \mathrm{Vgl}$. dazu Birg, Kohortenanalyse.

97 Zur hormonellen Verhütung vgl. Dose, Durchsetzung. 
Die einfache kausale Rückführung des Geburtenrückgangs auf die allgemeine Freigabe chemischer Verhütungsmittel ist jedoch nicht haltbar. Fragt man nach den Ursachen des Geburtenrückgangs, dann kann die Bereitstellung von Verhütungsmitteln nur dazu dienen, einen bereits bestehenden Verhütungswunsch zu realisieren, wird diesen Wunsch jedoch in aller Regel nicht selbst produzieren. In der Literatur der sechziger Jahre wurde häufig auch der zunehmenden Erwerbstätigkeit der Frauen eine Mitschuld am Geburtenrückgang zugeschrieben. ${ }^{98}$ Neuere Studien relativieren diesen Ansatz, da erst die Familien kleiner wurden und sich dann in der Folge andere Lebensmodelle, etwa in Form einer Erwerbstätigkeit, für Frauen ergaben. ${ }^{99}$ Die Veränderungen in der Lebenswelt der Frau hatten vielfältige Wechselwirkungen mit der Familie. Die traditionelle Rollenverteilung zwischen den Geschlechtern wurde dadurch aufgebrochen, vermeintlich jahrhundertealte transzendental begründete Familienmodelle in Frage gestellt.

\section{Arbeitsverhältnisse}

\section{Erwerbstätige Mütter: eine „ärgerliche Tatsache der Gesellschaft" ${ }^{100}$}

Zwischen 1950 und Mitte der siebziger Jahre gab es keine signifikante Veränderung der allgemeinen Frauenerwerbsquote in der Bundesrepublik. Sie stieg von 1950 bis 1960 von 30,2 Prozent auf 33,4 Prozent, fiel dann bis 1968 wieder auf 30,3 Prozent, um seither wieder leicht anzusteigen. 1976 waren 31,1 Prozent aller westdeutschen Frauen erwerbstätig. ${ }^{101}$ Dieser Befund, der nahezu eine Stagnation abbildet, muß allerdings vor dem Hintergrund demographischer Entwicklungen relativiert werden, denn der Anteil der Frauen, die über 65 Jahre alt und damit im Pensionsalter waren, erhöhte sich im selben Zeitraum erheblich. Für die KernAltersgruppe der 16- bis 60jährigen hat sich die Erwerbsquote von 44,4 auf 52,9 Prozent erhöht. ${ }^{102}$

Viel aufsehenerregender als dieser Anstieg war jedoch, daß sich unter den berufstätigen Frauen zunehmend Ehefrauen und Mütter befanden. War 1950 nur jede vierte verheiratete Frau berufstätig, so ging 1970 bereits gut jede dritte Ehefrau einer Erwerbstätigkeit nach. Anders gewendet: Während 1950 nur 19 Prozent aller erwerbstätigen Frauen verheiratet waren, betrug ihr Anteil 1961 bereits 35 Prozent und 1970 fast 50 Prozent. ${ }^{103}$ Dieser Anstieg lag zwar in einem Trend, der seit den achtziger Jahren des 19. Jahrhunderts andauerte, war aber in diesem

98 Schubnell, Entwicklung, S. 95; vgl. auch Schelsky, Wandlungen; Pfeil, Berufstätigkeit.

99 Vgl. Höhn, Erwerbstätigkeit, sowie die sehr differenzierte Argumentation bei Niehuss, Strukturgeschichte, S. 214-288.

100 Zitat nach Dahrendorf, Homo Sociologicus, S. 10.

101 Maier, Arbeitsmarkt, S. 259, Tabelle 1.

102 Vgl. Willms-Herget, Frauenarbeit, S. 88, Tab. 2.1. Zur Entwicklung der Erwerbstätigkeit von Ehefrauen und Müttern vgl. auch Niehuss, Strukturgeschichte, S. 223-263.

${ }^{103}$ Die Zahlen beziehen sich auf die "marktbezogene" Erwerbstätigkeit ohne mithelfende Familienangehörige. Willms, Grundzüge, S. 35, Tabelle 1. 
Ausmaß ein neues Phänomen. 104 Noch stärker war die Berufstätigkeit unter den Müttern angestiegen. Von 1950 bis 1971 erhöhte sich die absolute Zahl der erwerbstätigen Mütter in Westdeutschland von 1,5 Millionen auf 2,7 Millionen. ${ }^{105}$ 1950 war jede vierte Mutter in der Bundesrepublik berufstätig, Mitte der siebziger Jahre war es jede dritte. Der stärkste Anstieg fand dabei zwischen 1950 und 1961 statt. ${ }^{106}$ Gut 4,4 Millionen Kinder lebten 1971 in Familien, in denen die Mutter berufstätig war. ${ }^{107}$

Die Zunahme der Erwerbsquote bei Ehefrauen und Müttern war teilweise darauf zurückzuführen, daß die Ausbildungszeiten immer länger wurden und viele Frauen erst in einem Alter in den Beruf einstiegen, in dem sie üblicherweise bereits verheiratet waren - zumal gleichzeitig auch das durchschnittliche Heiratsalter sank. Das gestiegene Ausbildungsniveau zeigt sich beispielsweise in der zunehmenden Zahl der Studentinnen. Die Zahl der studierenden Frauen an den westdeutschen Universitäten und Hochschulen hat sich zwischen 1950 und 1975 von 25336 auf 282113 mehr als verzehnfacht. Zwar wuchs auch die Zahl der männlichen Studierenden während dieser Zeit, aber bei weitem nicht in vergleichbarem Ausmaß. Waren 1950 nur 19,7 Prozent aller Studierenden weiblich, so hatte sich die Quote 1975 auf 33,7 Prozent erhöht. ${ }^{108}$ Eine Stichprobenuntersuchung zeigt, daß auf der anderen Seite vor allem die Zahl der Frauen mit Hauptschulabschluß rückläufig war. ${ }^{109}$ Während in der Geburtskohorte der 1919-1921 geborenen Frauen 42,7 Prozent nur einen Hauptschulabschluß ohne Berufsausbildung hatten, verringerte sich deren Anteil bei der Geburtskohorte der 1954-1956 geborenen Frauen auf acht Prozent. Am stärksten nahm im Gegenzug die Zahl der Frauen mit Mittlerer Reife und Berufsausbildung zu. Ihr Anteil stieg von 15,2 Prozent auf 34,5 Prozent.

Die mit diesem Prozeß einhergehende Verlängerung der Ausbildungszeiten allein reicht jedoch als Erklärung für die Zunahme der Zahl der berufstätigen Ehefrauen und Mütter nicht aus. Offenbar sahen immer weniger junge Frauen die Eheschließung und Geburt eines Kindes als plausiblen Grund dafür an, ihre Erwerbstätigkeit zu beenden. Im Gegenteil: Gerade in der Anfangsphase der Familiengründung waren viele Anschaffungen zu machen und die Familie konnte ein zweites Einkommen gut brauchen. Aber nicht nur junge Ehefrauen waren erwerbstätig. Auch Frauen, die schon ältere Kinder hatten, stiegen ab Ende der fünfziger Jahre zunehmend wieder in das Berufsleben ein. Diese Frauen waren schon

104 Vgl. dazu Sommerkorn, Mutter, S. $116 \mathrm{f}$.

105 Schubnell, Entwicklung, S. 105 f. Die Zahl der erwerbstätigen Mütter bezogen auf Mütter von Kindern unter 15 Jahren, einschließlich des landwirtschaftlichen Bereichs.

106 Sommerkorn, Mutter, S. 116 f. Demnach wurden statistische Daten über die Erwerbstätigkeit von Müttern in der Bundesrepublik in der Zeitschrift „Wirtschaft und Statistik“ erstmals 1954 als Auswertung der Volkszählung 1950 veröffentlicht. Im statistischen Jahrbuch findet sich 1967 der erste Eintrag dazu. Erst seit 1971 wurden im Rahmen des Mikrozensus Daten nach einheitlichen Kriterien erhoben.

107 Schubnell, Entwicklung, Tabelle S. 104.

108 Führ/Furck, Bildungsgeschichte, S. 652, Tabelle 9.

109 Blossfeld, Wandel, S. 8. Zur kohortenspezifischen Aufteilung vgl. Niehuss, Strukturgeschichte, S. 228-230, $241 \mathrm{f}$. 
in den vierziger Jahren, kurz nach ihrer Eheschließung, erwerbstätig gewesen und hatten damals ihre ersten Erfahrungen mit der "Doppelrolle“ in Beruf und Haushalt gemacht. 110

Die Motivationsforschung konzentrierte sich bereits Anfang der fünfziger Jahre auf die Frage, welche Begründung Frauen, die eine Familie hatten, für ihre Erwerbstätigkeit anführten. In den Argumenten zeigte sich in der zweiten Hälfte der siebziger Jahre ein entscheidender Wandel. ${ }^{111}$ In den einschlägigen Studien der fünfziger Jahre, die allerdings die Frauen selbst kaum zu Wort kommen ließen, wurde die Erwerbstätigkeit von Müttern noch als Dienst für die Familie interpretiert: Die Frau könne die physische und psychische Überbelastung durch Familien- und Berufsarbeit nur ertragen, wenn sie „ihre Berufstätigkeit als Leistung und Pflicht gegenüber der Familie" verstehe. ${ }^{112}$ Auch als in den späten fünfziger Jahren die ersten direkten Befragungen von erwerbstätigen Müttern durchgeführt wurden, waren die Antworten durch die normative Tendenz der Fragestellungen in bestimmter Weise vorgeprägt. ${ }^{113} \mathrm{Bis}$ in die siebziger Jahre hinein legitimierten Mütter ihre Erwerbstätigkeit als wirtschaftliche Notwendigkeit. Berufsverbundenheit wurde nicht als „ein Stück eigenes Leben“ deklariert, sondern als „Dasein für andere ". ${ }^{114}$ In den sechziger und frühen siebziger Jahren trat die Diskrepanz zwischen Leitbild und faktischer Zunahme der Müttererwerbstätigkeit immer schärfer hervor. Zeitgenössische soziologische Untersuchungen konstatierten psychologische Probleme, modifizierten ihren methodischen Ansatz jedoch kaum. Erst Ende der siebziger Jahre zeichnete sich ein Perspektivenwechsel im Forschungsansatz ab: Die feministische Forschung erarbeitete einen neuen, subjektiven „doppelten Lebenszusammenhang" von Frauen, der über die bisher praktizierte einfache quantitative Addition zur „Doppelbelastung“ hinauswies. 115

Für die Situation der Familien hatte die Zunahme der berufstätigen Ehefrauen und Mütter gravierende Konsequenzen: Die Familien mußten damit leben lernen, daß die Ehefrau und Mutter nicht mehr ausschließlich für die Familienarbeit zur Verfügung stand. Arbeitgeber mußten sich damit arrangieren, daß ihre Mitarbeiterinnen in zunehmendem Maß neben ihren beruflichen Pflichten auch „Familienpflichten" hatten. Die Frauen mußten die Spannungen zwischen der Berufssphäre und der Familiensphäre, die sich in der typischen "Doppelbelastung“ der berufstätigen Mütter zeigte, ausbalancieren. Und die Familienpolitiker mußten ihre Perspektiven auf Bereiche erweitern, die jenseits des häuslichen Familienkrei-

$110 \mathrm{Vgl}$. Müller, Frauenerwerbstätigkeit, S. $70 \mathrm{f}$.

111 Vgl. dazu auch die Analyse zeitgenössischer soziologischer Untersuchungen zur Müttererwerbstätigkeit von Sommerkorn, Mutter.

112 Schelsky, Wandlungen, S. 312; Pfeil, Berufstätigkeit, S. $78 \mathrm{f}$. Vgl. zur Motivationsfrage in den fünfziger Jahren Niehuss, Strukturgeschichte, S. 250-256.

113 So wurde beispielsweise stets die Frage gestellt, warum Mütter denn erwerbstätig sein wollten, nicht dagegen die umgekehrte Frage, warum Mütter, wenn sie sich nicht gerade in der Phase aktiver Mutterschaft befanden, eigentlich nicht arbeiteten. Auf die intentionale Fragemethode hatten Myrdal und Klein in ihrer populären Studie über die Doppelrolle der Frau in Familie und Beruf bereits 1956 aufmerksam gemacht. Vgl. Myrdal/ Klein, Doppelrolle.

114 Vgl. dazu Beck-Gernsheim, Dasein.

115 Sommerkorn, Mutter, S. $136 \mathrm{f}$. 
ses lagen, und die Probleme der „Doppelbelastung“ der Hausfrauen und Mütter in ihr Programm integrieren. Die nach Kriegsende stark gestiegene Erwerbstätigkeit der Mütter gilt bis heute als ein Hauptproblem der Familienpolitik. ${ }^{116}$

Im Verhältnis zu anderen Teilgruppen der weiblichen Erwerbstätigen scheinen die Mütter zur Gruppe der Modernisierungsverlierer zu gehören. Dies zeigt ein Blick auf die Wirtschaftsbereiche, in denen die Mütter arbeiteten. Erwerbstätige Mütter gab es traditionell vorwiegend im landwirtschaftlichen Sektor oder als sonstige "mithelfende Familienangehörige" in Familienbetrieben, beispielsweise im Handel oder Handwerk. Etwa ab 1967 zeigte sich ein neuer Trend: Zunehmend befanden sich auch unter den abhängig beschäftigten Frauen Mütter mit Kindern unter 15 Jahren. Ihre Gesamtzahl hat sich dort zwischen 1950 und 1971 fast verfünffacht. ${ }^{117}$ Hinter dieser rasanten Zunahme verbirgt sich jedoch ein verlorenes Rennen für die Mütter. Denn insgesamt gesehen gelang den Müttern der Übergang in ein abhängiges Beschäftigungsverhältnis wesentlich seltener als kinderlosen Frauen. Zwischen 1950 und 1971 wanderten beispielsweise über zwei Drittel (67 Prozent) der kinderlosen Frauen aus der Landwirtschaft ab, während die Abnahme bei den Müttern (mit Kindern unter 15 Jahren) nur 41 Prozent betrug. 118

In den neuen abhängigen Beschäftigungsverhältnissen waren Teilzeitarbeit oder eine phasenweise Unterbrechung der Arbeit möglich. Dies waren Modelle, die in den sechziger Jahren etabliert wurden, um den Müttern zu helfen, Familie und Beruf zu bewältigen. Für "mithelfende Familienangehörige" hingegen gab es solche Möglichkeiten in der Regel nicht. Bei weitem nicht alle Mütter profitierten also von diesen vielpropagierten Lösungsmodellen. Die Mütter, die den Übergang nicht vollzogen, hatten zudem das Nachsehen bei der zunehmenden Integration der erwerbstätigen Bevölkerung in sozialversicherungsrechtlich abgesicherte Arbeitsplätze, die mit dem Wechsel von der Position der „mithelfenden Familienangehörigen " in ein abhängiges Beschäftigungsverhältnis verbunden war. Mit der eigenen sozialen Sicherung gewannen die Frauen eine Alternative zur vom Ehemann abgeleiteten Versorgung der "Nur-Hausfrau“. Dieser Effekt und das steigende Einkommen in besser qualifizierten Tätigkeiten förderten die Selbständigkeit der Frauen und stärkten ihre Position im innerfamiliären Machtgefüge. Gleichzeitig stiegen bei einem Ausscheiden aus dem Beruf zugunsten der Kindererziehung die "Opportunitätskosten“ der Frauen. Die Entscheidung zur Aufgabe der Berufstätigkeit bedeutete die Aufgabe der wirtschaftlichen Unabhängigkeit für den Augenblick, aber auch für die in der Ferne liegende Alterssicherung. Diese wirtschaftlichen Einbußen waren ein neuer Faktor, den die Familienpolitik in der zweiten Hälfte des zwanzigsten Jahrhunderts zunehmend berücksichtigen mußte.

116 Vgl. Lee, Familie, S. 129-173. Lee sieht in der Müttererwerbstätigkeit das Hauptproblem heutiger Familienpolitik. Dabei geht sie von einer „Erwerbsneigung“ der Frauen aus, die nicht nur auf wirtschaftlicher Not beruht, sondern auch im steigenden Bildungs- und Qualifikationsniveau der Frauen begründet ist. Aus der Müttererwerbstätigkeit leitet Lee zahlreiche Folgeprobleme ab, die die Familie in ihren gesellschaftlichen Funktionen gefährden.

117 Schubnell, Entwicklung, S. 107.

118 Ebenda, S. 106 f.; vgl. dazu auch Niehuss, Strukturgeschichte, S. 270-272. 
Allerdings bargen auch die neuen Arbeitsverhältnisse für die Ehefrauen und Mütter nicht nur Vorteile: Sie erzwangen eine rigidere Trennung zwischen Familie und Erwerbstätigkeit. Es war nun kaum mehr möglich, die Kinder "nebenher" zu betreuen. Geregelte Arbeitszeiten zwangen dazu, daß die Familie ihren Lebensrhythmus auf die Vorgaben des Arbeitsplatzes abstimmen mußte, während in der Landwirtschaft oder im eigenen Betrieb die Arbeitsbelastung zwar oft höher war, die Arbeitszeit aber etwas flexibler eingeteilt werden konnte. ${ }^{119}$

Die zunehmende Erwerbstätigkeit der Mütter hatte weitreichende Konsequenzen, denn sie stellte das traditionelle „Ernährer-Hausfrau/Zuverdienerin-Modell“ in Frage, das für die familienpolitische Restaurationsphase der fünfziger Jahre konstitutiv gewesen war. ${ }^{120}$ Dieses schon im 19. Jahrhundert entwickelte Gesellschaftsmodell schrieb Männern generell die Position als Ehemänner und Familienväter zu und sah Frauen in der Rolle der Hausfrauen und - falls sie erwerbstätig waren - als „Zuverdienerinnen“. Der Mann orientierte sich demnach primär an der Berufsrolle. Eine lebenslange, kontinuierliche und aufstiegsorientierte Berufsarbeit wurde als Norm männlicher Erwerbsarbeit angesehen. Entsprechend wichtig war die optimale Berufsausbildung. Als angemessene Einkommenshöhe für einen Mann, der stets als potentieller Familienvater galt, wurde der „Familienernährerlohn" angesehen, der auch für die Versorgung von Frau und Kindern ausreichte. Schließlich hatten Männer bei Arbeitsmarktengpässen aufgrund ihrer Pflichten gegenüber den anderen Familienmitgliedern im Vergleich zu weiblichen Konkurrenten einen bevorzugten Anspruch auf einen Arbeitsplatz. Für die Frau dagegen galt die Arbeit als Hausfrau und Mutter als "natürlicher" Beruf. Sie war wirtschaftlich vom „Familienernährer" abhängig. Außerhäusliche Erwerbstätigkeit von Frauen galt nach diesem Modell als Ausnahme, die nur in bestimmten Lebensphasen, in der Regel zwischen Ausbildungsabschluß und Eheschließung, toleriert wurde. Dieses Leitbild gehorchte damit dem Zwei-Phasen-Modell, wonach die Frauen eine kurze Lebensphase der Erwerbstätigkeit hatten, bis mit der Eheschließung die zweite Phase in der Familie folgte, die bis zum Lebensende dauerte. ${ }^{121}$ Entsprechend unterstellte man, daß Frauen keine beruflichen Aufstiegsambitionen hätten. Eine gute Berufsausbildung wurde für Frauen daher lange Zeit als nachrangig angesehen. Als angemessener Lohn galt der „Zuverdienerlohn“, der weit unter dem Niveau des „Familienernährerlohnes“ lag. Verbunden mit dieser komplementären Aufgabenaufteilung war eine Hierarchisierung der Geschlechter, die die Frau dem Mann unterordnete.

Dieses Modell war auch in der Mentalität der Zeitgenossen relativ fest verankert. So ergab beispielsweise eine Umfrage 1953, daß unter den Befragten 61 Prozent der jungen Männer, aber nur 28 Prozent der jungen Frauen den Wunsch

$119 \mathrm{Zu}$ dem Befund, daß es auch in Familienbetrieben und vor allem in der Landwirtschaft die vermeintliche familienfreundliche Idylle, in der die Kinder während der Arbeit mitbetreut werden konnten, immer weniger gab, vgl. Kuller, Stiefkind, S. $295 \mathrm{f}$.

$120 \mathrm{Vgl}$. zum folgenden Hausen, Frauenerwerbstätigkeit.

121 Eine Sondersituation, in der die Erwerbstätigkeit von Hausfrauen und Müttern toleriert und sogar politisch erwünscht wurde, war auch die Kriegszeit. Vgl. dazu Stoehr, Frauenerwerbsarbeit. 
hatten, beruflich voranzukommen. 12226 Jahre später ergab die Umfrage zum gleichen Thema, daß inzwischen 43 Prozent der Frauen und nur 41 Prozent der Männer beruflichen Fortschritt anstrebten. Es waren auch durchaus nicht nur die Männer, die das traditionelle Familienmodell unterstützten. Zeitgenössische soziologische Untersuchungen bestätigen, daß auch viele der erwerbstätigen Frauen den Wunsch hatten, ihren Beruf möglichst bald aufzugeben und als „Nur-Hausfrau in das Heim zurückzukehren“. ${ }^{123}$ Man muß die Selbstaussagen der Frauen ernst nehmen, denn sie spiegeln, wie verinnerlicht die Rollenzuschreibungen waren. Gleichzeitig muß jedoch berücksichtigt werden, daß bei der Entscheidung für oder gegen eine Erwerbstätigkeit auch die Haltung der anderen Familienmitglieder, das gesellschaftliche Ansehen und die Erwartungshaltung der Umgebung eine wichtige Rolle spielten. Hinzu kommt: Erwerbstätigkeit war für die Ehefrau und Mutter immer eine Zusatzbelastung. Ihre Verpflichtung zur Haushaltsführung und Kindererziehung blieb unverändert weiter bestehen. Das manifestierte sich auch darin, daß die alleinige Verantwortung der Hausfrau für die Haushaltsführung im Rahmen der Familienrechtsreform 1957 nur gemildert, aber erst 1976 aufgehoben wurde. ${ }^{124}$

Der Ausbruch aus dem „Ernährer-Hausfrau/Zuverdienerin-Modell“ führte zu Problemen in den Familien. Naheliegend war die Frage nach einer Umverteilung der "Familienarbeit", die nun nicht mehr automatisch auf den Schultern der Frau ruhen mußte, falls diese ebenso wie der Familienvater außer Haus erwerbstätig war. Hier zeigte und zeigt sich allerdings bis heute eine starke Beharrungskraft des Leitbildes, denn in Familien mit erwerbstätigen Müttern wurde nicht etwa die Familienarbeit selbstverständlich neu aufgeteilt, sondern primär den Frauen eine "Doppelbelastung" durch häusliche Aufgaben als Hausfrau und Mutter und durch die außerhäusliche Erwerbstätigkeit zugemutet. ${ }^{125}$

Zudem stellte eine Abkehr vom Leitbild in letzter Konsequenz auch die innerfamiliäre Autoritätsverteilung in Frage. Das Entscheidungsrecht in Familienfragen, das gemäß dem Familiengesetz beim Ehemann und Vater lag, leitete sich letztlich daraus ab, daß der Mann der Versorger der Familie und ihr Vertreter gegenüber der Außenwelt war. Wenn die Frau nun aber ebenfalls zur wirtschaftlichen Versorgung der Familie beitrug, mußte sich die Frage nach der Legitimation der Position des Vaters stellen. Besonders brisant war in diesem Zusammenhang das Recht des Ehemannes, über die Erwerbstätigkeit seiner Frau zu bestimmen

122 Umfrageergebnisse nach Elisabeth Noelle-Neumann, Die Verwandlung der Frauen, in: dies./Edgar Oiel, Eine Generation später, S. 16-19, zitiert nach Ritter, Deutschland, S. 111.

123 Vgl. beispielsweise Schelsky, Wandlungen, S. 310. Bestätigt wurde diese These noch in Prokop, Lebenszusammenhang, S. 45.

124 Vgl. Limbach, Entwicklung, S. 17-19; Schwab, Gleichberechtigung, S. 805-812.

125 Das Bild der "Verdopplung" von Lasten und Leistungen für die Frauen findet sich in dreierlei Hinsicht: In der „Doppelbelastung“ durch gleichzeitige Familienarbeit und Erwerbstätigkeit, im Vorwurf des „Doppelverdieners“, wonach bei Ehepaaren, in denen beide Partner erwerbstätig waren, stets die Frau die "Doppelverdienerin“ war, und schließlich in der Frage der „Doppelversorgung“ der Frauen, die sowohl vom Ehemann abgeleitet als auch aufgrund der eigenen Erwerbstätigkeit Ansprüche an die Sozialversicherung hatten. Vgl. dazu auch Böke/Stötzel, Doppelverdiener. 
bzw. diese auch gegen den Willen der Frau zu kündigen, wenn die Frau ihre „Familienpflichten" nicht ausreichend erfüllte. Diese Regelung wurde erst mit der Familienrechtsreform 1957 aufgehoben.

Prägend war das Modell auch als Leitbild der Sozialversicherung, die für Hausfrauen und Kinder eine vom Vater als "strong-male-breadwinner" abgeleitete soziale Sicherung vorsah. Im Gegensatz zu den erwerbstätigen Müttern konnten die „Nur-Hausfrauen" keine eigenen Ansprüche auf Sozialversicherung geltend machen. Als immer mehr Ehefrauen und Mütter berufstätig wurden und sich damit die Option für eine eigene Sicherung eröffneten, stellte sich die Frage, wie die nun entstandene Benachteiligung der „Nur-Hausfrauen“ kompensiert werden sollte: Entweder durch eine allgemeine Berufstätigkeit möglichst vieler Mütter - eine Lösung, die grob gesprochen dem sozialdemokratischen Modell entsprach. Die Konsequenz waren kompensatorische Entlastungsleistungen der Gesellschaft wie Kindergärten oder in weitergehenden Modellen Gemeinschaftsküchen und gemeinschaftliche Wohnformen. Die zweite Alternative bestand darin, möglichst alle Mütter zumindest während der „Familienphase“ für „Familienarbeit“ freizustellen, indem Anreize dafür gegeben wurden, daß die Frauen bei der Geburt eines Kindes die Erwerbstätigkeit aufgaben. Neben dem Familienlastenausgleich, der die finanzielle Situation der jungen Familien entspannen sollte, ist hier vor allem die Verschärfung des Scheidungsrechtes im Jahr $1961 \mathrm{zu}$ nennen, die eine spätere „Verstoßung" der Ehefrau aus der vom Ehemann abgeleiteten sozialen Sicherung erschweren sollte. Diese Lösung wurde von den Unionsparteien favorisiert. Die dritte Alternative, den Müttern eine freie Wahlmöglichkeit zu eröffnen, indem eine der Berufstätigkeit adäquate soziale Sicherung und ein angemessener Ausgleich der „Opportunitätskosten“ auch für „Familienphasen“ gesetzlich zugesichert waren, wurde erst seit Mitte der achtziger Jahre ernsthaft erwogen und ist bis heute nur ansatzweise verwirklicht. Einen vorläufigen Kompromiß bildete die Teilzeitarbeit, die bis Ende der sechziger Jahre als sozialversicherungsrechtlich geregeltes Arbeitsverhältnis etabliert wurde und der Frau gleichzeitig eine Erfüllung ihrer „Familienpflichten“ erlaubte.

Eine Allianz unterschiedlicher gesellschaftlicher Kräfte stand der zunehmenden Erwerbstätigkeit der Mütter kritisch gegenüber. Soziologen befürchteten, daß die Frauen durch die Berufstätigkeit ihre typischen Eigenschaften verlieren würden. ${ }^{126}$ Gemäß der Theorie polarer Geschlechtscharaktere wurden den Frauen Wesensmerkmale wie Passivität, Duldsamkeit, Schwäche und Gefühlsbetontheit zugeschrieben. Bei der Aufrechterhaltung der geschlechtlich definierten Grenzlinie zwischen Familie und außerhäuslicher Erwerbstätigkeit ging es daher nicht nur um die Erhaltung männlicher Macht, sondern auch um die Angst vor dem Verlust der Emotionalität, die als spezifisch weiblich angesehen wurde. Diese Zuschreibung der weiblichen Charaktermerkmale führte gleichzeitig zu einer Verschleierung des Arbeitscharakters der Hausarbeit. ${ }^{127}$ "Aus Liebe“ sollten die Frauen die Familienarbeit erledigen - das hieß de facto: unentgeltlich.

126 Vgl. dazu Schütze, Erwerbstätigkeit.

127 Meyer/Schulze, Frauen, S. 182. Vgl. dazu grundlegend Hausen, Polarisierung. 
Von medizinischer Seite wurden ebenfalls Bedenken gegen die Müttererwerbstätigkeit erhoben. ${ }^{128}$ Nicht alle warnenden Ärzte gingen dabei soweit wie der Göttinger Frauenarzt Heinz Kirchhoff, der in Anknüpfung an die Debatten nationalsozialistischer Mediziner gesundheitliche Schädigungen der erwerbstätigen Frauen bis hin zur Sterilität befürchtete. ${ }^{129}$ Mit seiner Forderung nach einem Verbot außerhäuslicher Erwerbsarbeit für Mütter von Kindern unter $15 \mathrm{Jahren}$, das er 1961 auf der Tagung der Internationalen Organisation der Familienverbände in Madrid formulierte, stand Kirchhoff weitgehend allein. ${ }^{130}$ Sein Heidelberger Kollege Alexander Rüstow, der ein Arbeitsverbot für Mütter mit Kindern im Alter von bis zu sechs Jahren forderte, fand hingegen auch bei den Bonner Familienpolitikern Gehör, allerdings nur im Zusammenhang mit der besonderen Situation der unvollständigen Familie. ${ }^{131}$ Die Schadens-Prognosen Rüstows und Kirchhoffs bezogen sich dabei nicht nur auf die erwerbstätigen Frauen selbst. Vor allem ab Anfang der sechziger Jahre kam als zusätzliche Befürchtung die „Maternal Deprivation", die für das Kind schädliche Trennung von der Mutter hinzu. 132

Von Bedeutung waren auch die Interventionen der christlichen Kirchen. Während die katholische Kirche der Erwerbstätigkeit unverheirateter Frauen durchaus positiv gegenüberstand, ${ }^{133}$ hatte sie der Ehefrau und Mutter die Aufgabe zugeschrieben, sich uneingeschränkt der Familie zu widmen. Die Familie sollte "Kirche im kleinen" sein und die intensive Vermittlung christlicher Werte an die nächste Generation gewährleisten. Nachdem im Nationalsozialismus viele gesellschaftliche Institutionen diskreditiert worden waren, sah man in der Familie nahezu die einzige integere und intakte Institution, die zur Reorganisation der Gesellschaft geeignet war. Den Frauen war dabei die Funktion der Kindererziehung zugewiesen. Sie sollten die Hauptverantwortung für ein Gelingen der christlichen Prägung der neuen Generation tragen.

Ein harmonisierendes Modell, das sich schließlich in christlichen Kreisen und in den konservativen Parteien als Lösung für das Dilemma der Frauen zwischen Beruf und Familie durchsetzte, war das Drei-Phasen-Modell, das Alva Myrdal und Viola Klein entwickelt hatten. ${ }^{134}$ Der entscheidende Schritt, den das Modell von Myrdal und Klein ermöglichte, war der von der „Doppelbelastung“ zur „Doppelrolle“. Die Frau sollte nicht mehr gleichzeitig Familien- und Erwerbsarbeit leisten, sondern phasenweise versetzt. So sah das Modell eine erste Phase weiblicher Erwerbstätigkeit bis zur Eheschließung oder bis zur Geburt des ersten Kindes vor. Danach folgte eine Phase, in der sich die Frau nur der Familie wid-

$128 \mathrm{Vgl}$. dazu Ruhl, Unterordnung, S. $178 \mathrm{ff}$.

129 Kirchhoff, Belastung, S. 1308.

$130 \mathrm{Vgl}$. Ruhl, Unterordnung, S. 178, Fußnote 242.

131 Hans Harmsen auf der Sitzung des wissenschaftlichen Beirats beim Bundesfamilienministerium am 28. 4. 1961, BAK, B 195/27.

132 Der Begriff „Maternal Deprivation“ wurde 1951 von John Bowlby im Zusammenhang mit der kriegsbedingten Trennung von Mutter und Kleinkind geprägt. Vgl. Schütze, Erwerbstätigkeit, S. $124 \mathrm{f}$.

133 Vgl. Rölli-Alkemper, Familie, S. 110-112.

134 Erst nach der Übersetzung ins Deutsche 1960 wurde das Buch auch in der Bundesrepublik rezipiert; Myrdal/Klein, Doppelrolle. 
mete. Nachdem die Kinder das Elternhaus verlassen hatten, sollte die Frau ihre Erwerbstätigkeit wieder aufnehmen. Kirchen und christliche Verbände griffen den Gedanken auf, und bis Mitte der sechziger Jahre hatte sich das Drei-PhasenModell als Leitbild katholisch-konservativer Familienpolitik durchgesetzt. Ein Indikator für die Durchsetzung des Leitbildes war die Konjunktur von Angeboten zur beruflichen Wiedereingliederung älterer Frauen, denn Maßnahmen, die sich mit der Wiedereingliederung beschäftigten, setzten voraus, daß eine frühere Erwerbstätigkeit vorhanden gewesen war, die zwischenzeitlich - in der Regel zugunsten von Familienarbeit - unterbrochen worden war.

In der Realität gab es jedoch wenige Frauen, deren Lebenslauf dem Schema des Zwei- oder Drei-Phasen-Modells entsprach. ${ }^{135}$ Bei den Frauen, die in den fünfziger Jahren, unter dem Vorzeichen des Zwei-Phasen-Modells, mit der Familiengründung ihre Erwerbstätigkeit beendeten und sich nach der Familienphase mit dem neuen Leitbild des Drei-Phasen-Modells auseinandersetzen mußten, zeigte sich keine Zwei- oder Drei-Phasen-Ordnung, sondern eine Vielphasigkeit der Biographien, häufig mit mehrfachen Wechseln zwischen Beruf und Familie. Die Verteilung auf die unterschiedlichen Clustermuster orientierte sich nicht - wie zu erwarten gewesen wäre - an der familiären Situation oder den wirtschaftlichen Verhältnissen, sondern hauptsächlich an der Berufsgruppe, der die Frau angehörte. Nicht nur die Familiensituation, nicht so sehr die Einstellung des Ehemannes und auch nicht allein die ökonomischen Zwänge entschieden häufig über einen Wiedereinstieg in den Beruf, sondern vor allem der erlernte Beruf: Zur entscheidenden Frage wurde, ob es im Berufsfeld üblich war, auch als ältere Frau zu arbeiten.

\section{„Schlïsselkinder": \\ das Problem der Betreuung von Kindern erwerbstätiger Mütter}

War die Mutter berufstätig, dann zeigten sich die Folgen ganz besonders für die Kinder, die während der Abwesenheit der Mutter anderweitig betreut werden mußten. Öffentliche Hilfen, vor allem Kindergartenplätze, standen nicht in ausreichendem Maße zur Verfügung. Aber auch die Legionen der "Schlüsselkinder“, die infolge des Mangels an Kindergarten- und Hortplätzen die Straßen hätten bevölkern müssen, gab es nicht. ${ }^{136}$ Vielmehr organisierten die Mütter private Arrangements, so daß die meisten Kinder bei Verwandten oder Freunden unterkommen konnten.

135 Vgl. zum folgenden Born u.a., Wandel; Teilergebnisse auch in Born, Ei vor Kolumbus; Born, Bedeutung.

136 In der öffentlichen Diskussion stand die Zahl von rund 3 Mio. „Schlüsselkindern“ im Raum, die unter anderem der Kinderarzt Theodor Hellbrügge durch eine pauschalisierende Berechnung ermittelte: Er addierte zu den rund 1,8 Mio. Kindern, die bei alleinerziehenden Müttern lebten, die Zahl der Kinder erwerbstätiger Mütter hinzu, die auf rund 2 Mio. geschätzt wurde. Diese Zahl war jedoch völlig aus der Luft gegriffen und wurde bereits durch zeitgenössische Untersuchungen widerlegt. Vgl. Niehuss, Strukturgeschichte, S. 256-259. 
Die Frage, wer die Kinder während der Abwesenheit der Mütter betreute, stand in den fünfziger und vor allem in den sechziger Jahren im Zentrum der öffentlichen Aufmerksamkeit. In einer Zeit, in der Erziehung und Bildung zunehmend zu Schlüsselbegriffen für gesellschaftlichen Fortschritt und steigenden Wohlstand wurden, mußten die vermeintlich unbetreuten Kinder der erwerbstätigen Mütter zum Politikum werden. Die Legende der „Schlüsselkinder“ rief daher nicht nur moralische, sondern auch gesellschaftspolitische Kritiker auf den Plan. Da in dieser Studie die Kindergartenpolitik des Landes Bayern als Fallbeispiel untersucht wird, soll Bayern in den Blick genommen werden, um die Situation der Kinder erwerbstätiger Mütter zu beleuchten. ${ }^{137}$

Hedwig A. Herrmann kam 1954/55 in einer Stichprobenuntersuchung über die Erwerbstätigkeit verheirateter Frauen und Mütter in Bayern zu dem Ergebnis, daß nur drei von 100 Kindern unter sechs Jahren während der Abwesenheit der

Tabelle 4: Betreuung der Kinder erwerbstätiger Mütter in Bayern 1954/55-1969 (Prozent):138

\begin{tabular}{|c|c|c|c|c|c|c|}
\hline \multirow[t]{2}{*}{ Jahr } & \multicolumn{3}{|c|}{$\begin{array}{c}\text { nicht schulpflichtige Kinder } \\
\text { unter } 6 \text { (7) Jahre } \\
\text { Vormittag/Nachmittag }\end{array}$} & \multicolumn{3}{|c|}{$\begin{array}{c}\text { schulpflichtige Kinder } \\
6(7)-15 \text { Jahre }\end{array}$} \\
\hline & $\begin{array}{l}\text { Betreuung } \\
\text { durch } \\
\text { Familien- } \\
\text { mitglieder }\end{array}$ & $\begin{array}{l}\text { Betreuung } \\
\text { durch } \\
\text { Institution } \\
\text { (inkl. Kin- } \\
\text { dergarten) }\end{array}$ & Unbetreut & $\begin{array}{l}\text { Betreuung } \\
\text { nachmittags } \\
\text { durch } \\
\text { Familien- } \\
\text { mitglieder }\end{array}$ & $\begin{array}{l}\text { Betreuung } \\
\text { nachmittags } \\
\text { durch Insti- } \\
\text { tution (inkl. } \\
\text { Kinderhort) }\end{array}$ & Unbetreut \\
\hline $1954 / 55$ & 48,6 & $\begin{array}{l}47,5 \\
\text { (davon } \\
\text { 31,3 Kin- } \\
\text { dergarten) }\end{array}$ & 2,9 & 33,1 & $\begin{array}{l}35,4 \\
\text { (davon } \\
22,8 \mathrm{Kin}- \\
\text { derhort) }\end{array}$ & 29,9 \\
\hline 1962 & $81,5 / 83,4$ & $18,3 / 16,5$ & $0,2 / 0,1$ & 58,9 & 31,9 & 9,2 \\
\hline 1969 & $79,3 / 81,7$ & $18,1 / 15,7$ & 2,6 & 67,5 & 21,2 & 11,3 \\
\hline
\end{tabular}

137 Die Lage der außerhäuslichen Betreuungsmöglichkeiten für Kleinkinder war in den Bundesländern sehr unterschiedlich. Vgl. dazu auch Kapitel V.2 dieser Studie. Zu den durchschnittlichen Werten im Bundesgebiet vgl. Niehuss, Strukturgeschichte, S. 256263.

138 Daten für 1954/55 nach der Fragebogenumfrage von Herrmann, Erwerbstätigkeit. Die empirische Basis von 536 Frauen mit insgesamt 659 Kindern unter 15 Jahren ist nicht sehr breit. Die Zeilensummen in der Tabelle ergeben nicht 100 Prozent, weil einige Fragebögen nicht korrekt ausgefüllt wurden. Die Betreuungskategorien Herrmanns weichen von denen der amtlichen Statistik etwas ab. So unterscheidet Herrmann zwischen familieneigener und fremder Betreuung, unter die auch Kindertagesstätten gerechnet werden. Die amtliche Statistik unterscheidet dagegen zwischen Betreuung durch Institutionen und durch Einzelpersonen. Die Zäsur zwischen vorschul- und schulpflichtigem Alter setzt Hermann außerdem nach dem 7. Lebensjahr, die amtliche Statistik dagegen nach dem 6. Lebensjahr. Daten für 1962 nach Engel, Frauen, S. 116. Daten für 1969 nach Fischbach, Betreuung, S. 26. 
Mutter „ohne jegliche Betreuung“ blieben. Immerhin knapp ein Drittel der Kinder besuchte einen Kindergarten. Bei den Schülern war dagegen nach ihren Untersuchungen fast jedes dritte Kind nachmittags unbeaufsichtigt. Als 1962 in Bayern erstmals flächendeckend amtliche Daten zur Erwerbstätigkeit von Müttern erhoben wurden, ${ }^{139}$ ergab sich acht Jahre nach der Studie von Herrmann ein etwas anderes Bild: So gut wie keine Mutter gab an, daß ihr Kleinkind während ihrer Abwesenheit ohne Betreuung sei. Auch unter den Schülern blieb nur etwa jeder zehnte nachmittags auf sich allein gestellt. Nur knapp 20 Prozent der Kleinkinder gingen jedoch in den Kindergarten - eine wesentlich geringere Quote als Herrmann ermittelt hatte. Der Rest war vormittags in der Obhut von Verwandten, in der Regel bei der Großmutter. Mag die Statistik auch nicht immer ganz zuverlässig sein - denn welche Mutter hätte schon freiwillig angegeben, daß ihre Kinder stundenlang unbeaufsichtigt waren -, so kann doch festgestellt werden, daß die öffentliche Kinderbetreuung nur eine geringe Rolle spielte und daß Nachbarschafts- und Verwandtschaftshilfe offenbar viel besser funktionierten, als Kritiker der Müttererwerbsarbeit vermutet hatten.

Die Verhältnisse unterschieden sich zwischen Stadt und Land erheblich. ${ }^{140} \mathrm{Je}$ größer eine Gemeinde war, desto größer war auch die Chance, eine ganztägige institutionelle Betreuung für die Kinder zu finden. In Städten mit mehr als 100000 Einwohnern hatte rund ein Drittel der Kinder einen Ganztagsplatz, in Gemeinden unter 2000 Einwohnern war die Quote nur halb so hoch, obwohl hier der Bedarf höher gewesen wäre: In diesen Orten hatten nämlich fast 30 Prozent der erwerbstätigen Frauen Kinder, meist sogar mehrere, in Großstädten dagegen nur 18 Prozent. Auf dem Land spielte daher die Betreuung durch Privatpersonen eine größere Rolle. Meist sprangen Verwandte ein, die dort enger zusammenlebten und sich deshalb besser als in den Städten gegenseitig aushelfen konnten.

Das Ergebnis, daß 1962 nur sehr wenige Kinder ohne Aufsichtsperson waren, erstaunt vor allem dann, wenn man bedenkt, wie selten und wie kurz Kleinkinder in Kindergärten gingen. Vormittags waren es 18 Prozent, nachmittags 17 Prozent. 1969 hatte sich die Situation gegenüber 1962 nicht wesentlich verändert. Die noch nicht schulpflichtigen Kinder erwerbstätiger Mütter wurden immer noch weitgehend von Familienangehörigen betreut. Der Anteil der Kindergartenbesucher war nahezu gleich niedrig geblieben.

Die Konzeption der Betreuung lief in vielen Punkten an den Bedürfnissen der erwerbstätigen Mütter vorbei. Das begann damit, daß nur ein geringer Teil der Kinder den ganzen Tag über im Kindergarten bleiben konnte, auch öffnete der Kindergarten häufig zu spät oder schloß früher, als die Arbeitszeit der Mütter begann oder endete. Hinzu kam, daß der Kindergarten ein intensives Engagement der Mütter forderte, sei es in Form von ehrenamtlicher Hilfe, sei es in der Elternarbeit. Das Ziel der Kindergärten war aber auch nicht die Entlastung der erwerbstätigen Mütter, sondern eine „familienergänzende" Bereicherung der Kindererziehung. Bei weitem nicht bei allen Kindern, die einen Kindergarten besuchten, war die Mutter erwerbstätig.

139 Engel, Frauen, S. 116.

140 Vgl. ebenda. 
Um sich ein Bild von der Rolle des Kindergartens im alltäglichen Familienleben zu machen, soll die erste flächendeckende statistische Erhebung über Kindergärten in Bayern aus dem Jahr 1969 näher betrachtet werden. ${ }^{141}$ Zunächst fällt ins Auge, daß 183400 bayerische Kinder einen Kindergarten besuchten, daß es aber insgesamt statistisch gesehen nur 170600 Plätze gab. Dieser auf den ersten Blick paradoxe Befund erklärt sich dadurch, daß sich oft zwei Kinder einen Kindergartenplatz teilten, indem ein Kind vormittags kam und eines nachmittags. Die sogenannte „Mehrschichtentagesstätte“ war gängige Praxis. Ein Viertel aller Kinder hielt sich nur einen halben Tag im Kindergarten auf. In den privaten Kindergärten wurde sogar nur die Hälfte der Kinder ganztags aufgenommen.

Auch die ganztags betreuten Kinder erhielten mehrheitlich kein Mittagessen im Kindergarten. Obwohl in der Hälfte der Einrichtungen die Möglichkeit zum Mittagessen bestand, nahmen nur 21 Prozent der Kinder diese Gelegenheit wahr. Ein Teil der übrigen Kinder ging mittags heim, um dort eine warme Mahlzeit einzunehmen. In der Mehrzahl der Fälle war das kein Problem, da die Mutter nicht erwerbstätig war. Nur bei einem Drittel der Kindergartenkinder arbeiteten beide Eltern. ${ }^{142}$ War die Mutter mittags nicht zuhause, dann sprangen meist Verwandte ein.

Mit Hilfe der Beitragszahlungen kann man darauf schließen, welche Klientel überwiegend die Kindergärten besuchte. Die Elternbeiträge für die Halbtagskindergärten lagen nämlich höher als die für Ganztagskindergärten. Das Ergebnis erklärt sich u.a. daraus, daß die Kinder der Halbtagsbetreuung in der Regel aus wohlhabenderen Familien stammten, deren Eltern daher einen höheren Beitrag leisten mußten. Dies zeigt sich bei allen Trägergruppen und Arten von Kindergärten durchgehend.

94 Prozent der Kinder in den Kindergärten stammten aus vollständigen Familien. Die alleinerziehenden Mütter, die einer Erwerbstätigkeit nachgehen mußten und daher einen Kindergartenplatz für ihre Kinder brauchten, spielten statistisch gesehen in Bayern also nur eine relativ geringe Rolle. Sie fanden einen Betreuungsplatz für ihre Kinder meist in den Betriebskindergärten von Firmen. Hier beobachtete man einen doppelt so hohen Anteil, nämlich zehn Prozent. ${ }^{143}$ Als pädagogisch besonders wichtig wurde der Kindergartenbesuch für Einzelkinder angesehen. Tatsächlich waren rund ein Viertel aller Kindergartenkinder Einzelkinder (27 Prozent). Fast ebenso viele stammten aber aus sogenannten kinderreichen Familien mit drei und mehr Kindern (23 Prozent).

\section{Der Wandel des bäuslichen Arbeitsbereichs}

Immer mehr Ehefrauen und Mütter waren berufstätig, obwohl ihre Verpflichtung als Hausfrau und Mutter in der Familie sowohl im gesellschaftlichen Rollenverständnis als auch vor dem Familiengesetzbuch bestehen blieb. Die Erwerbstätigkeit führte dazu, daß im Zeitbudget der Frauen weniger Zeit für die „Familien-

141 Zum folgenden vgl. Arnold, Kindertagesstätten.

142 Ebenda, S. 35.

143 Ebenda, S. 34. 
pflichten", d. h. für Haushalt und Kindererziehung, blieb. Führte die zunehmende Verbreitung von elektrischen Geräten zu einer Erleichterung und Zeitersparnis, die den Frauen die Möglichkeit gaben, Hausarbeit und Berufstätigkeit zu verbinden? Hatte die gleichzeitige Technisierung des Haushalts für den Aufgabenbereich der Hausfrau und Mutter in diesem Sinne eine emanzipationsfördernde Wirkung? Untersuchungen zu dieser Frage kommen einhellig zu dem Ergebnis, daß sich trotz der zunehmenden Verbreitung technischer Haushaltsgeräte der zeitliche Aufwand für Haus- und Erziehungsarbeit kaum verringerte. Im Gegenteil - die konstant hohen "materiellen" Aspekte der Hausarbeit und die sogar noch zunehmenden "sozialen“ Arbeitsanforderungen sorgten für eine Zunahme der für die Erfüllung der Familienaufgaben nötigen Arbeit. ${ }^{144}$

Es steht außer Zweifel, daß sich der Arbeitsplatz der Hausfrau seit dem Ende des Zweiten Weltkriegs erheblich veränderte. Die Verbreitung von Kühlschränken und die Einführung von Supermärkten als neuer Ladenform erleichterten Einkäufe und Vorratshaltung. ${ }^{145}$ Durch längere Anfahrtszeiten und fehlende Beratung ging aber der Zeitgewinn letztlich häufig wieder verloren, zumal die Ansprüche an die Hausfrau stiegen, abwechslungsreich und ernährungsbewußt einzukaufen. Im Hinblick auf die Einführung von Kühlschränken und neue Ladenformen kann man also von einem Rationalisierungsprozeß sprechen. Der Zeitgewinn wurde aber durch gestiegene Ansprüche und unübersichtlicheres Angebot wieder zunichte gemacht. In anderen Bereichen, beispielsweise bei den Kleinküchengeräten, war das Rationalisierungspotential von vornherein sehr gering. Die elektrischen Geräte konnten nur für einzelne Schritte eingesetzt werden und keine ganzen Arbeitsprozesse ersetzen. Aufbau, Nutzung, Reinigung und Abbau dauerten oft mindestens genauso lang, wie wenn man den Vorgang per Hand erledigte. Gleichzeitig erhöhten sich aber auch in diesem Bereich die Ansprüche: eine abwechslungsreiche und gesunde Küche war gefragt. So fällt die Zeitbilanz im Küchenbereich im Vergleich zwischen den fünfziger und den sechziger Jahren trotz der gestiegenen Zahl der Küchengeräte zuungunsten der Hausfrau aus.

Waschmaschinen dagegen erleichterten die Hausarbeit ganz erheblich. ${ }^{146}$ Auch hier stiegen jedoch gleichzeitig mit der Rationalisierung des Waschvorganges die Ansprüche, so daß kaum ein Zeitgewinn zustande kam. Dabei stand die Erhöhung des Standards und Bedarfs zwar in Zusammenhang mit der Technisierung, war aber keine unmittelbare Technikfolge, denn bereits in den fünfziger Jahren, als Waschmaschinen in Privathaushalten noch wenig verbreitet waren, erhöhte sich die Wäschemenge und es wurde häufiger gewaschen.147 Der Putzaufwand wurde aufgrund der zunehmenden Wohnungsgröße höher, was durch den Erwerb eines Staubsaugers in der Regel nicht wettgemacht werden konnte. Insgesamt sank

144 Meyer/Schulze, Längsschnittuntersuchung, S. 35.

145 Vgl. dazu Hellman, Keller. Die steigende "Konsumarbeit" beispieisweise bei Preis-Leistungs-Vergleichen wurde auch durch die zunehmende Verbreitung von Fertigprodukten nicht wettgemacht. Vgl. Meyer/Schulze, Längsschnittuntersuchung, S. 28.

146 Zur sozialgeschichtlichen Bedeutung der Einführung der Waschmaschine vgl. Hausen, Wäsche; Silberzahn-Jandt, Wasch-Maschine; Orland, Wäsche.

147 Meyer/Schulze, Längsschnittuntersuchung, S. 27. 
selbst bei erwerbstätigen Frauen der wöchentliche Zeitaufwand für Hausarbeit nicht unter 45 Stunden pro Woche. Bei Nur-Hausfrauen stieg die wöchentliche Arbeitszeit seit 1950 eher noch an. ${ }^{148}$

Die „soziale“ Arbeit, d.h. vor allem Kinderbetreuung und -erziehung, wurde ebenfalls von der zunehmenden Technisierung beeinflußt. ${ }^{149}$ Auf der einen Seite war die materielle Versorgung von Kindern erleichtert durch die Waschmaschine, fließendes Warmwasser, und auch durch die Einführung von industriell gefertigter (Baby)Nahrung. Auf der anderen Seite zeigte sich die Alltagswelt immer weniger kindgerecht. Zwischen der Kindergeneration der sechziger und der siebziger Jahre tat sich eine Kluft auf. Während die Kinder in den sechziger Jahren - zumindest auf dem Land - noch relativ problemlos unbeaufsichtigt "draußen" spielen konnten, war das in den siebziger Jahren zu gefährlich geworden. Die Zeiten für Kinderbetreuung haben sich dadurch erhöht. Auch Radio, Fernseher und Plattenspieler prägten den Kinderalltag ab den sechziger Jahren. Dadurch erhöhten sich Erziehungs- und "Aushandlungs"-Zeiten für einen angemessenen Medienumgang. Als Fazit bleibt der Befund, daß sich durch die Technisierung zwar der materielle Teil der Kinderversorgung erleichtert hat. Die erhöhten Ansprüche an die Sozialisation und der Betreuungsaufwand haben diese Zeitersparnisse aber wieder weitgehend aufgebraucht. Insgesamt hat der Zeitaufwand für Kindererziehung und -betreuung sogar zugenommen. ${ }^{150}$

Offenbar kann man von der zunehmenden Technisierung der Hausarbeit nicht auf eine quantitative, qualitative oder zeitliche Abnahme der Arbeitsbelastung schließen. ${ }^{151}$ Die durch Rationalisierung eingesparte Arbeitszeit wurde wieder reinvestiert. In einer Hinsicht hat die Technisierung aber dennoch eine entlastende Wirkung gehabt: Sie führte zu mehr Zeitsouveränität.152 Der große Fortschritt durch den Einsatz der Waschmaschine beispielsweise bestand darin, daß der Zeitpunkt der Wäsche nicht mehr an einen Wochentagsrhythmus gebunden war, sondern daß zu einem individuell günstigen Zeitpunkt gewaschen werden konnte. Auf diesen Effekt beziehen sich auch die Thesen, die davon sprechen, daß die

148 Ebenda, S. 29 f.

149 Ebenda, S. 30-35.

150 Meyer/Schulze, Frauen, S. $179 \mathrm{f}$.

151 Das "Haushaltsparadoxon", daß die nach Taylorschen Prinzipien durchgeführte technische Modernisierung des Haushaltes letztlich kaum zu Rationalisierungseffekten führte, liegt nicht nur an den gleichzeitig gestiegenen Ansprüchen, sondern auch an den unterschiedlichen strukturellen Vorgaben von industrieller und Haushaltsproduktion. In der Industrie beschreibt Rationalisierung den Vorgang, daß ein Arbeitsprozeß in Einzelschritte aufgeteilt und auf mehrere Arbeitskräfte, die durch die Spezialisierung ihre Produktivität steigern, verteilt wird. Im Haushalt bleiben dagegen alle Arbeitsschritte bei der Hausfrau als einziger Person. Im Gegenteil: Wo früher Kooperation zumindest zwischen Familienmitgliedern nötig war - beispielsweise beim Wäschewaschen oder Kochen wurden die Hausfrauen sogar noch zunehmend isoliert. Produktivitätssteigerung konnte im Haushalt kaum realisiert werden, weil sich die Hausfrau nicht spezialisierte - sie blieb „Mädchen für alles“. Außerdem können die Arbeitsprozesse im Haushalt nicht zu größeren Produktionseinheiten zusammengefaßt werden, wie das in der industriellen Fabrik der Fall ist. Vgl. dazu Kettschau, Arbeit; Dörr, Frauen.

152 Vgl. Garhammer, Zeitsouveränität. 
Technisierung des Haushalts eine außerhäusliche Erwerbsarbeit von Ehefrauen und Müttern überhaupt erst möglich gemacht habe. Hausarbeit konnte an die Ränder des Tages vor und nach der Arbeitszeit verlegt werden. Zeitgenössische Studien belegen auch, daß erwerbstätige Frauen Ende der fünfziger Jahre im allgemeinen eine Stunde vor und drei bis vier Stunden nach der Erwerbsarbeit den Haushalt erledigten. ${ }^{153}$ Durch die flexiblere Zeitgestaltung ist es aber gleichzeitig nötig geworden, Hausarbeiten bewußt zu planen, zu organisieren und zu koordinieren, was wieder zusätzlich Zeit kostete.

Die geschlechtsspezifische Rollenaufteilung wurde durch die Technisierung der Haushalte eher verfestigt als aufgebrochen. 154 Tätigkeitsbereiche im Haushalt, die früher von Männern übernommen worden waren, wurden vielfach außer Haus erledigt und externalisiert (z. B. Mehlmahlen). Gab es für einen Vorgang ein technisches Gerät, dann zogen sich die Männer im allgemeinen aus diesem Bereich, auch wenn sie vorher mitgeholfen hatten, ganz zurück und überließen das Feld der Frau. Durch die Technisierung war es überhaupt erst möglich, die geschlechtsspezifische Arbeitsteilung trotz zunehmender Berufstätigkeit verheirateter Frauen beizubehalten. Die einzige nennenswerte Erhöhung der Beteiligung von Männern betraf die Kinderbetreuung und -erziehung. ${ }^{155}$ Gerade der emotionale Teil der „Familienarbeit" entzog sich aber weitgehend einer Technisierung und Rationalisierung. ${ }^{156}$ Zusammenfassend bleibt festzuhalten, daß sich die Technisierung und Rationalisierung der Hausarbeit unabhängig vom tatsächlichen Bedarf überlasteter Hausfrauen und Mütter vollzog und trotz mancher entlastenden Wirkung im Einzelfall höchst ambivalente Wirkungen zeigte.

\section{Teilzeitarbeit als Kompromiß zwischen beruflichen und familiären Anforderungen}

Frauen haben schon immer neben ihren „Familienpflichten“ gearbeitet, oft als mithelfende Familienangehörige, in haushaltsnahen (Pflege)Bereichen oder im saisonalen Zuerwerb. Die Debatte um die Teilzeitarbeit in den fünfziger und sechziger Jahren drehte sich daher weniger um die Entwicklung der tatsächlichen stundenweisen Erwerbstätigkeit, sondern um die Integration dieser Arbeit in das System der sozialen Sicherung. Die sozialversicherte Teilzeitarbeit ermöglichte es auch Frauen mit Familie, an dem System der sozialen Sicherung teilzuhaben. Dadurch gerieten jedoch die „Nur-Hausfrauen“ und Mütter ins Abseits, die nur indirekt abgesichert und von ihrem Mann in diesem Punkt abhängig waren.157

153 Pfeil, Berufstätigkeit. Vgl. zur Situation in den fünfziger Jahren Wildt, Konsumgesellschaft, S. 126-131.

154 Vgl. zum folgenden Dörr, Frauen, und ausführlich dies., Aneignung. Vgl. zur These der rollenverstärkenden Wirkung des Technisierungsprozesses auch Hausen, Nähmaschine; dies., Wäsche.

155 Meyer/Schulze, Längsschnittuntersuchung, S. 38.

156 Methfessel, Arbeitskraft.

157 Die sozialstaatliche Anerkennung und Würdigung der Tätigkeit der Hausfrau und Mutter tauchte als familienpolitische Frage bereits zu Anfang der sechziger Jahre auf, aber erst in den siebziger Jahren setzte sich die Politik ernsthaft mit dem Problem auseinander. 
Bereits in der Nachkriegszeit bildete die Teilzeitarbeit ein Kompromißmodell, das Müttern neben ihren „Familienpflichten“ die Möglichkeit geben sollte, selbst Geld zu verdienen und eine soziale Sicherung zu erwerben. Kriegswitwen mit Kindern wurde in der Nachkriegszeit nach dem sogenannten „ErsatzernährerModell“ zeitweise sogar ein Anspruch auf einen Halbtagsarbeitsplatz zugesprochen, um ihnen die Möglichkeit zu geben, die Rolle des „Ernährers“ der Familie selbst zu übernehmen. ${ }^{158}$ Was für die verwitweten Frauen, die Kinder zu versorgen hatten, angehen mochte, schien den Politikern jedoch für verheiratete Ehefrauen und Mütter kaum akzeptabel. Vor allem in Zeiten hoher Arbeitslosigkeit wurden diese erwerbstätigen Frauen mit heftigen Vorwürfen konfrontiert. Als im Winter 1949/50 beispielsweise die Arbeitslosigkeit in Bayern einen Höhepunkt erreichte, machten manche Betroffene eine einfache Rechnung auf: Wenn man die Erwerbstätigkeit verheirateter Frauen gesetzlich einschränkte, hätte man genügend freigewordene Arbeitsplätze, um das Problem der Arbeitslosigkeit zu lösen. ${ }^{159}$ Das bayerische Arbeitsministerium lehnte eine solche Regelung 1950 nach längerem Zögern aber endgültig ab. ${ }^{160}$ Eine Einschränkung der Erwerbstätigkeit verheirateter Frauen hätte - ganz abgesehen von ihrer verfassungsrechtlichen Bedenklichkeit - auch nicht zu dem gewünschten Effekt geführt, denn zwei Drittel der Ehefrauen arbeiteten als mithelfende Familienangehörige, meist in landwirtschaftlichen Betrieben. ${ }^{161}$ Dort waren sie kaum durch eine beliebige andere Arbeitskraft ersetzbar. Aus diesem Beispiel kann man jedoch ersehen, daß im Verteilungsmechanismus der knappen Arbeitsplätze nach Kriegsende manche Arbeitgeber und Politiker offenbar trotz des Männermangels der Nachkriegszeit immer noch davon ausgingen, daß Frauen sich auch indirekt über eine Eheschließung „versorgen“ konnten.

Dahinter stand die Vorstellung, daß Eheschließung und Erwerbstätigkeit alternative Versorgungsmöglichkeiten für Frauen darstellten. War eine erwerbstätige Frau verheiratet, galt sie als „Doppelverdienerin“, die einem anderen Mann den Arbeitsplatz wegnahm, der davon wiederum eine Frau bzw. Familie hätte miter-

Beispielsweise beschäftigte sich die Kommission „Kinder aus unvollständigen Familien“ des Beirats für Familienfragen beim Bundesfamilienministerium im April 1961 mit der Frage. Vgl. dazu Kapitel II.1. Eine erste, breit rezipierte, kritische Bestandsaufnahme bildete aber das Kapitel über die soziale Sicherung der Frau in der Frauenenquete von 1966. Konkrete Maßnahmen schlug beispielsweise der Beirat beim Bundesfamilienministerium im Februar 1970 vor. Vgl. Wissenschaftlicher Beirat beim Bundesministerium für Jugend, Familie und Gesundheit: Vorschläge zur sozialen Sicherung der Frau, in: Bulletin Nr. 20 vom 13. 2. 1970, S. 194-195.

158 Ansätze, für die Kriegswitwen ein „Ersatzernährer-Modell“ zu etablieren, das Halbtagsarbeit für Frauen mit kleinen Kindern vorsah, scheiterten aber bis 1950 weitgehend. Das Bundesversorgungsgesetz vom Dezember 1950 schuf eine Alternativlösung, die sich ganz auf die sozialstaatliche Versorgung der Kriegswitwen konzentrierte. Vgl. dazu v. Oertzen, Teilzeitarbeit, S. 41-54.

159 Vgl. dazu die Debatte um das "Doppelverdienertum“ in der bayerischen SPD 1948-1950, AdsD, SPD-Landtagsfraktion Bayern, 504.

160 Stellungnahme des bayerischen Arbeitsministeriums zur Frage des „Doppelverdienertums" vom Mai 1950, AdsD, SPD-Landtagsfraktion Bayern, 504.

161 Zopfy, Mehrfachverdiener, S. 218. 
nähren können. ${ }^{162}$ Erwerbstätige verheiratete Frauen waren „Doppelverdiener“ in zweifachem Sinn: Zum einen hatte der Haushalt zwei Erwerbseinkommen, zum anderen war die Frau doppelt "versorgt " durch die gesetzlich verankerte „Hausfrauenehe“ und ihr eigenes Einkommen. Diskutiert wurde die Frage der Frau als „Doppelverdienerin“ vor allem in Zeiten materieller Not und hoher Arbeitslosigkeit, wie es die späten vierziger und frühen fünfziger Jahre waren. Auch wenn das familienpolitische Leitbild noch bis Ende der sechziger Jahre daran festhielt, daß der „natürliche Beruf der Frau“ der der Hausfrau und Mutter sei, verbesserten sich die Möglichkeiten, einer Erwerbstätigkeit nachzugehen in Zeiten eines Arbeitskräftemangels, wie er seit Ende der fünfziger Jahre in der Bundesrepublik vorherrschte. ${ }^{163}$ In den Jahren des wirtschaftlichen Aufschwungs warben Unternehmen geradezu um Frauen mit "Familienpflichten“ als letzte Arbeitsmarktreserve. Einen Versuch, das Problem der „Doppelbelastung“ erwerbstätiger Mütter zu lösen, stellt die Institutionalisierung der Teilzeitarbeit für Frauen in den sechziger Jahren dar. ${ }^{164}$ Hier manifestierte sich eine Umwertung der Erwerbsarbeit von verheirateten Frauen von der Last der doppelten Arbeit zur „Lust am Zuverdienen“. Arbeitete die Frau nur halbtags, dann schien es möglich, weiterhin die „Familienpflichten“ zu erfüllen und gleichzeitig an den Vorzügen der Erwerbswelt teilzuhaben. Während 1957 nur 17 Prozent aller außerhäuslich erwerbstätigen Frauen weniger als 40 Stunden arbeiteten, waren es 1965 bereits ein Viertel. ${ }^{165}$ Dabei war Teilzeitarbeit nicht unbedingt gleichbedeutend mit Halbtagsarbeit. Viele Frauen arbeiteten drei Tage in der Woche voll und hatten die anderen Tage frei. Im Laufe der sechziger Jahre wurde die Teilzeitarbeit sozialversicherungsrechtlich so abgesichert, daß sie zwar als eine Form der Erwerbstätigkeit anerkannt wurde, aber gleichzeitig eine abgegrenzte Sonderform blieb, die in einem ergänzenden Verhältnis zur Familienrolle der Frau stand.

Den Startschuß gab das Bundessozialgericht, das 1962 entschied, daß Frauen ein Recht auf Arbeitslosenunterstützung hätten, wenn sie in der Lage wären, mindestens 25 Stunden in der Woche zu arbeiten. Bis dahin verweigerten die Arbeitsämter häufig die Arbeitslosenunterstützung, wenn die Frauen nicht "normal“, d.h. vollzeitig, einer Erwerbstätigkeit nachgehen konnten. ${ }^{166}$ Drei Jahre später wurde die Teilzeitarbeit auch als reguläres Beschäftigungsverhältnis in der Renten- und Krankenversicherung verankert. ${ }^{167}$ Eine Gleichstellung der Erwerbstätigkeit von Männern und Frauen im Steuerrecht traf jedoch von Anfang an auf heftigen gesellschaftlichen Widerstand von allen Seiten und war letztlich nicht durchsetzbar. Die 1960 probeweise eingeführte Sondersteuerklasse „F“ für Ehefrauen wurde dagegen sofort von der Bevölkerung akzeptiert. Zwar wurde der Lohn der Ehefrau mit höheren Steuern belegt. Diesen Preis waren aber beide Ehe-

162 Vgl. zum folgenden Böke/Stötzel, Doppelverdiener.

163 So beispielsweise Niehuss, Strukturgeschichte, S. 217-219, und Ruhl, Unterordnung, S. 291-296.

164 Vgl. die Studie von v. Oertzen, Teilzeitarbeit.

165 Niehuss, Strukturgeschichte, S. 245.

166 v. Oertzen, Teilzeitarbeit, S. 164.

167 Ebenda, S. 123-132. 
partner offenbar bereit zu zahlen, wenn dadurch der Status des Ehemannes als "Haupternährer" nicht durch einen Steuerklassenwechsel in Frage gestellt wurde. Mit der Einführung der Steuerklasse „F“ wurde zunächst nur das Recht auf einen „Zuverdienst“ etabliert. ${ }^{168}$ Bereits hierin zeigt sich, daß es nicht darum ging, die geschlechtsspezifische Arbeitsteilung radikal aufzubrechen. Vielmehr fügte sich das Modell der Teilzeitarbeit in das herrschende Frauenleitbild ein und ermöglichte gleichzeitig eine Integration der erwerbstätigen Frauen in das soziale Sicherungsnetz. Die Erwerbstätigkeit der Frau erhielt dabei den Charakter eines Konsumguts und paßte so perfekt in die Lebenswelt der „modernen“ Hausfrau der sechziger Jahre. So resümiert von Oertzen: „Die ,kleine Büroarbeit ' bereicherte in diesem Entwurf das Leben der professionellen Konsumentinnen wie ein Accessoire. Die vormals entgegengesetzten Pole von Hausarbeit und Erwerbsarbeit verschmolzen in der Warenwelt zu einer virtuellen Einheit, in der der Wunsch, berufstätig zu sein, zum Konsumbedürfnis umgedeutet und verharmlost wurde." 169

Langfristig zeigte sich, daß die Teilzeitarbeit keine ausreichende soziale Sicherung für die Frauen brachte. Auch wenn man berücksichtigt, daß eine Teilzeitbeschäftigung naturgemäß keine soziale Sicherung in gleichem Umfang wie eine Vollzeiterwerbstätigkeit bewirken kann, kamen die Frauen unterdurchschnittlich schlecht davon. Das hängt mit charakteristischen Prinzipien des Rentensystems der Bundesrepublik zusammen. Zwar ist das Rentensystem grundsätzlich geschlechtsneutral. In der Konzeption finden sich jedoch Voraussetzungen für die Teilhabe, die „den faktischen arbeitsmarktpolitischen, kulturellen und subjektiven Ausschluß der Frau“ bedeuteten. ${ }^{170}$ Frauen scheiterten an der Vorgabe der Mindestdauer der Erwerbstätigkeit, am propagierten - und sozialpolitisch geförderten - Familienleitbild, beispielsweise, wenn sie sich ihre früher gezahlten Beiträge bei der Eheschließung auszahlen ließen, oder an Arbeitsmarktstrukturen, wenn sie in Branchen arbeiteten, in denen kein Arbeitgeberanteil gezahlt wurde, etwa in der Landwirtschaft. Hinzu kommt, daß das Rentenversicherungssystem „Erwerbslücken“ bei Männern stärker ausgleicht (zu 60 Prozent) als bei Frauen (zu 12 Prozent): ${ }^{171}$ Typische Ausgleichszeiten werden für Ausbildung und Wehr- bzw. Kriegsdienst gewährt. Auch für Frauen gibt es inzwischen Ausgleichsleistungen für typische Ereignisse des Lebensverlaufs, d.h. für Ehe und Kinder. Aber in der rückschauenden Bilanz der Geburtsjahrgänge 1919-1921 zeigt sich: Je größer die Unterbrechungen der Erwerbsbiographie und die damit verbundenen Schwierigkeiten beim Wiedereinstieg in das Berufsleben waren, desto niedriger war die Erwerbsrente der Frau. Die Sozialversicherung förderte also die individuelle Alterssicherung des Mannes und die ehebezogene, indirekte Alterssicherung der Frau. ${ }^{172}$

Mit der Teilzeitlösung schien Ende der sechziger Jahre ein Ausweg gefunden, um die grundsätzlichen Probleme der Müttererwerbstätigkeit zunächst zu umge-

\footnotetext{
168 Ebenda, S. 187-209.

169 Ebenda, S. 319 f.

170 Riedmüller, Rechte, S. 46.

171 Allmendinger, Lebensverlauf, S. $169 \mathrm{f}$.

172 Ebenda, S. 197.
} 
hen. Die Teilzeitarbeit brach die stereotypen Argumentationen gegen die Erwerbstätigkeit von Hausfrauen und Müttern auf. Gleichzeitig blieb sie geschlechtsspezifisch konnotiert und führte nicht zu einer neuen Verteilung von Hausarbeit und Erwerbsarbeit zwischen den Ehepartnern. Im Gegenteil: Durch die Harmonisierung der Lebensbereiche Beruf und Familie wurden die Probleme der erwerbstätigen Mütter zunächst oberflächlich entschärft. Mit der Einrichtung der neuen Arbeitsform, die den Frauen sowohl die Haushaltsführung als auch eine eingeschränkte Berufstätigkeit ermöglichte, wurde die traditionelle Rollenverteilung in der Familie letztlich jedoch stabilisiert.

\section{Der Wandel der Familienstrukturen und die Familienpolitik}

Zusammenfassend bleibt festzuhalten, daß es in der unmittelbaren Nachkriegszeit zahlreiche demographische und soziale Indikatoren gab, die auf eine Krise der Familie als gesellschaftliche Kerninstitution hindeuteten. Etwa seit der Währungsreform stabilisierten sich die Verhältnisse aber wieder zunehmend. Der Anstieg der Eheschließungen, der signifikante Rückgang der Scheidungen nach 1948 und das anschließende Verharren der Scheidungsquote auf niedrigem Niveau sowie der Babyboom in den sechziger Jahre trugen erheblich dazu bei, daß sich parallel zum Wirtschaftswunder - und nicht ohne Zusammenhang - eine Art Familienwunder abzeichnete, das die familienpolitischen Bemühungen seitens der Politiker und Kirchenvertreter mit Erfolg zu krönen schien.

Waren die fünfziger Jahre also trotz der Kriegsfolgen eine Zeit der Rekonstruktion für die traditionelle bürgerlich-christliche Familie mit ihrer klaren geschlechtsspezifischen Rollenverteilung und einem Alleinerziehungsrecht der Eltern, so setzte in den sechziger Jahren eine Phase des Strukturwandels ein. Weniger Ehen wurden geschlossen, immer mehr jedoch geschieden. Die Familien hatten weniger Kinder und immer mehr Ehefrauen und Mütter wollten sich nicht mehr mit der ihnen zugedachten Rolle abfinden, die sie auf den häuslichen Handlungskreis beschränkte.

In der Zeit zwischen 1950 und 1975 hat sich die Quote der erwerbstätigen Ehefrauen und vor allem die der berufstätigen Mütter mit kleinen Kindern signifikant erhöht. Bemerkenswert ist allerdings, daß viele der Mütter letztlich zu den Modernisierungsverlierern gehörten: Ihnen gelang in weitaus geringerem Umfang als dem gesellschaftlichen Durchschnitt der Übergang in ein sozialversicherungsrechtlich abgesichertes Arbeitsverhältnis. Arbeiteten sie weiterhin als "mithelfende Familienangehörige", dann blieben ihnen nicht nur die unabhängige soziale Sicherung, sondern meist auch die zeitgenössischen Lösungsmodelle für das $\mathrm{Di}$ lemma der Doppelbelastung von Haushalt und Beruf verschlossen.

Die zunehmende Berufstätigkeit der Mütter rührte an den Grundfesten des westdeutschen Familienleitbildes. Nach dem „Ernährer-Hausfrau/Zuverdienerin-Modell" stand ihnen eine Erwerbstätigkeit außer Haus nur in dem Maße zu, in dem es ihre familiären Pflichten zuließen - in der Regel also nicht, solange kleine Kinder zu versorgen waren. Brachen die Frauen dieses Modell auf, dann stellten 
sie damit gleichzeitig die oberste Autorität des Familienvaters in Frage, denn diese leitete sich aus seiner Rolle als wirtschaftlicher Versorger der Familie her. Außerdem stand eine Neuaufteilung der „Familienarbeit“" zur Debatte, nachdem die Mutter ja ebenso wie der Vater eine Ernährer-Rolle übernahm. Dieser Aufbruch betraf nicht nur die innerfamiliären Beziehungen. Auch zentrale Sozialstaatsregelungen beruhten auf dem traditionellen Familienmodell. Sie sahen für die Mütter eine vom Ehemann und Vater abgeleitete soziale Sicherung vor. Diese Konstruktion war durch die zusätzliche eigenständige Sicherung der berufstätigen Mütter in Frage gestellt. Nach langen Aushandlungsprozessen kam es schließlich in Form der Teilzeitarbeit zu einem gesellschaftlich akzeptierten Modell der Erwerbstätigkeit für Ehefrauen und Mütter.

Parallel zur Zunahme der berufstätigen Mütter kann man einen Prozeß der Technisierung und Rationalisierung in den Familienhaushalten beobachten. Dieser ermöglichte in gewissem Maße erst die Berufstätigkeit, indem er den Müttern die notwendige Zeitsouveränität zur Verfügung stellte. Die Hausarbeit - als wichtigster Posten wohl das Wäschewaschen - konnte nun entsprechend den Anforderungen der Berufstätigkeit an die Ränder des Tages verlegt werden. Allerdings wäre es ein Trugschluß, zu glauben, daß es mit der Technisierung und Rationalisierung insgesamt zu einer Verringerung der Belastung gekommen wäre. Gleichzeitig stiegen nämlich die Ansprüche und es entstanden neue Hausarbeitsbereiche, die die Zeit- und Arbeitsersparnisse in der Regel kompensierten.

Warum, so könnte man fragen, beschäftigte sich die Politik mit diesen Entwicklungen? Die Veränderungen der Familienstrukturen spielten sich weitgehend in einem privaten Sektor ab, der nach dem zeitgenössischen Verständnis nicht zu den genuinen staatlichen Regelungsbereichen gehörte. Inwiefern also zog der beschriebene Wandel Folgen nach sich, die eine politische Intervention erforderten? Diese Frage richtet den Blick auf die Motive der Familienpolitik und deutet auf fünf staatliche Interessen im Bezug auf die Familien hin.

Einmal wurden bestimmte Leistungen der Familien, vor allem die Erziehung von Kindern und die Pflege von Alten und Kranken, von der Gesellschaft selbstverständlich vorausgesetzt. Waren diese Funktionen der Familie gefährdet, dann drohten kaum zu bewältigende finanzielle und organisatorische Belastungen beispielsweise in Form von Betreuungs- und Pflegeeinrichtungen - auf den Staat zuzurollen. In diesem Zusammenhang zielten familienpolitische Maßnahmen darauf, die Institution Familie und ihre Funktionstüchtigkeit zu erhalten. Dieses institutionelle Motiv geht davon aus, daß die Familie als Grundform menschlichen Zusammenlebens erhalten bleiben muß, weil sie unersetzlich für das Funktionieren der Gesellschaft ist. ${ }^{173}$

Hinzu kam ein Gerechtigkeitsempfinden, wonach spezifische Benachteiligungen der Familienmitglieder, die ihnen durch die „Familienarbeit“ entstanden, ausgeglichen werden sollten. In den fünfziger Jahren zielte diese Argumentation vor allem auf finanzielle Hilfen für die Familien. Der „Familienlohn“ für eine vielköpfige Familie sollte sich vom „Individuallohn“, der nur eine Person versorgte, deut-

173 Die Bezeichnung der unterschiedlichen familienpolitischen Motive findet sich ähnlich bei Herlth/Kaufmann, Probleme, S. 14-18; Vgl. auch Kaufmann, Zukunft, S. 140. 
lich unterscheiden. Ein zweiter wichtiger Punkt war später auch ein Ausgleich für Mütter, die sich phasenweise während der Kindererziehung aus der Erwerbstätigkeit zurückzogen und dadurch gegenüber Alleinstehenden mit einer durchgehenden Erwerbsbiographie, benachteiligt waren. Dieses Argument wird als sozialpolitisches Motiv bezeichnet. Im Hintergrund steht der Gedanke, daß Kinder Träger der zukünftigen wirtschaftlichen Prosperität sind. Die kinderlosen Erwerbstätigen erschleichen sich daher einen Vorteil, indem sie die Kosten für Kinder sparen, und hoffen, später trotzdem von der nachfolgenden Generation profitieren zu können.

Anders argumentierten die Befürworter einer emanzipatorischen Familienpolitik. Das emanzipatorische Motiv bezieht sich auf die einzelnen Familienmitglieder und deren Stellung und Entfaltungsmöglichkeiten innerhalb der Familie. Der Staat, so lautet hier die Forderung, sei verpflichtet, die Lebenschancen für alle Menschen zu optimieren, unabhängig von der Rolle, die sie in ihrer Familie haben. Naturgemäß zielte die emanzipatorische Familienpolitik zunächst auf die schwächeren Familienmitglieder: Das waren die Ehefrauen und Mütter, später auch die Kinder. Hier wird allerdings schon die Problematik dieses Ansatzes sichtbar: Die Interessen der Frauen und der Kinder standen sich beispielsweise in der Frage der Müttererwerbstätigkeit in gewissem Maße entgegen, was dazu führte, daß die Familienpolitik hier Kompromisse schließen mußte und sich dann entweder dem Vorwurf der Frauen- oder der Kinderfeindlichkeit ausgesetzt sah.

Der Staat war außerdem dann auf den Plan gerufen, wenn seine sozialen Regelungen durch den Wandel der Familienstrukturen gefährdet waren. Im Bereich der Sozialversicherung beispielsweise sah man Probleme in zweierlei Hinsicht: Zum einen konterkarierten die berufstätigen Mütter die rechtliche Konstruktion der vom Familienvater abgeleiteten sozialen Sicherung. Sie unterliefen damit nicht zuletzt auch die Argumentation konservativer Familienpolitiker, die unter Berufung auf das traditionelle Familienmodell einen Ausbau der abgeleiteten Sicherung forcieren wollten. Zum anderen basierte das Sozialversicherungssystem auf einem Generationenvertrag in einer demographisch stabilen Gesellschaft. Es gab und gibt bis heute daher ein gesamtgesellschaftliches Interesse daran, daß genug Kinder heranwachsen, um den Generationenvertrag weiter zu tragen. Dies ist quasi eine sozialökonomische Variante des bevölkerungspolitischen Motivs. Wenn die Altersstruktur der Bevölkerung sich in der Weise verschiebt, daß die Zahl der älteren, nicht mehr im Erwerbsleben stehenden Personen wächst, während es immer weniger junge Menschen gibt, die im produktiven Alter sind, gerät der soziale Zwei-Generationenvertrag aus dem Gleichgewicht. Das bedeutet nicht nur, daß immer weniger einzahlende Personen die Rentenversicherung für immer mehr alte Menschen finanzieren müssen und dadurch die Höhe der Sozialabgaben kaum mehr als generationell ausgewogen bezeichnet werden kann, sondern führt gesamtwirtschaftlich gesehen auch dazu, daß die Produktivität der Wirtschaft sinkt, während ein wachsender Teil der Bevölkerung nur noch konsumtiv daran teilnimmt.

Schließlich gab es über diese Sachargumente hinaus wertkonservative Gründe für familienpolitische Interventionen. Vor allem für christlich geprägte Politiker bildete die Familie als vorstaatliche Institution einen Wert an sich. Sie sollte nicht 
durch sich ändernde ökonomische Rahmenbedingungen in Frage gestellt werden. Gefährdeten neue ökonomische und gesellschaftliche Entwicklungen die traditionellen Familienstrukturen, dann mußten in den Augen dieser Politiker ausgleichende Gegenmaßnahmen ergriffen werden. Diese Argumentation bildet eine Variante des institutionellen Motivs mit transzendentaler Herleitung, denn die Familie wurde dabei als von Gott gegebene Lebensweise aufgefaßt, um deren Bedürfnisse herum sich die Gesellschaft organisieren müsse.

Veränderungen der Familienstrukturen lassen sich auf drei Ebenen ausmachen: im demographischen Bereich, im Feld der sozialen Beziehungen und schließlich im ökonomischen Sektor. Betrachtet man diese drei Bereiche aus der Perspektive der Familienpolitik, dann zeigt sich, daß sie der politischen Intervention nicht in gleichem Maße zugänglich waren. Dem politischen Zugriff entzogen waren die demographischen Zäsuren, die durch äußere Ereignisse verursacht worden waren, sowie deren generationenübergreifende Eigendynamik. Auf andere Bereiche ökonomische Rahmenbedingungen, soziale Beziehungen, zunehmend aber auch die individuellen Wertvorstellungen - meinten die Familienpolitiker hingegen Einfluß nehmen zu können. Welcher Methoden sie sich dabei bedienten und ob sie dabei erfolgreich waren, diese Fragen sind Gegenstand der folgenden Kapitel. Daß eine Analyse der Veränderungen der Familienstrukturen am Anfang dieser Studie steht, soll nicht den Eindruck erwecken, als ob zwischen sozialer Veränderung und politischer Reaktion ein einseitiges Ursache-Wirkungs-Verhältnis bestünde. Vielmehr gab es komplexe Wechselbeziehungen zwischen Politik und sozialer Lage. An dieser Stelle soll zudem betont werden: Die Entwicklung der Familienstrukturen in der Bundesrepublik hat immer wieder unerwartete Wendungen genommen, und es gibt viele Tendenzen, in denen sich kaum Ursache-Wirkungs-Bezüge festmachen lassen. In dieser Hinsicht zeigt die Familie viel „Eigensinn“. ${ }^{174}$ Auf der anderen Seite erweist sich aber auch, daß die Familienpolitik oft so stark wertgeleitet war, daß sie sich den empirischen Gegebenheiten nur begrenzt öffnen konnte. Auch die Familienpolitik hat also ihren „Eigensinn“.

174 Lüscher, Annäherungen, S. 30-34. 
